\title{
Gas Bubble Retention Modeling for High-Level Waste Tanks
}

by

A. H. Weber

Westinghouse Savannah River Company

Savannah River Site

Aiken, South Carolina 29808

F. G. Smith

R. J. Kurzeja

J. H. Weber

DOE Contract No. DE-AC09-96SR18500

This paper was prepared in connection with work done under the above contract number with the U. S.

Department of Energy. By acceptance of this paper, the publisher and/or recipient acknowledges the U. S.

Government's right to retain a nonexclusive, royalty-free license in and to any copyright covering this paper, along with the right to reproduce and to authorize others to reproduce all or part of the copyrighted paper. 


\section{DISCLAIMER}

This report was prepared as an account of work sponsored by an agency of the United States Government. Neither the United States Government nor any agency thereof, nor any of their employees, makes any warranty, express or implied, or assumes any legal liability or responsibility for the accuracy, completeness, or usefulness of any information, apparatus, product, or process disclosed, or represents that its use would not infringe privately owned rights. Reference herein to any specific commercial product, process, or service by trade name, trademark, manufacturer, or otherwise does not necessarily constitute or imply its endorsement, recommendation, or favoring by the United States Government or any agency thereof. The views and opinions of authors expressed herein do not necessarily state or reflect those of the United States Government or any agency thereof.

This report has been reproduced directly from the best available copy.

Available to DOE and DOE contractors from the Office of Scientific and Technical Information, P.O. Box 62, Oak Ridge, TN 37831; prices available from (615) 576-8401.

Available to the public from the National Technical Information Service, U.S. Department of Commerce, 5285 Port Royal Road, Springfield, VA 22161. 


\section{DISCLAIMER}

\section{Portions of this document may be illegible in electronic image products. Images are produced from the best available original document.}


WSRC-TR-99-00159

May 1999

\section{Gas Bubble Retention Modeling for High-Level Waste Tanks(U)}

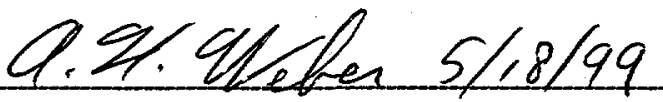

A. H. Weber, Author, MTD/NTS

Westinghouse Savannah River Company

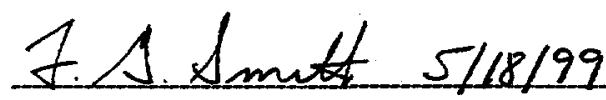

F. G. Smith, Author, PC\&C/ITS

Westinghouse Savannah River Company

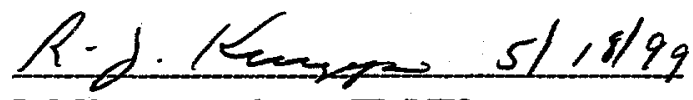

R. J. Kurzeja, Author, MTD/NTS

Westinghouse Savannah River Company

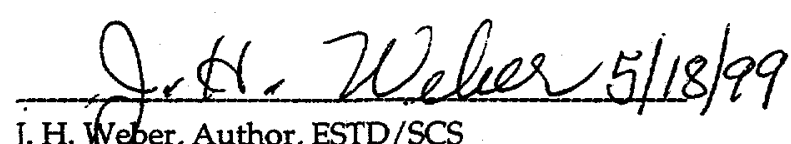

J. H. Weber, Author, ESTD/SCS

Westinghouse Savannah River Company

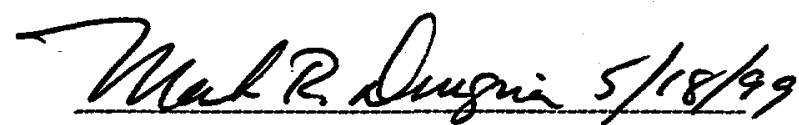

M. R. Duignan, Technical Reviewer, ETF/ED

Westinghouse Savannah River Company
Approved by:

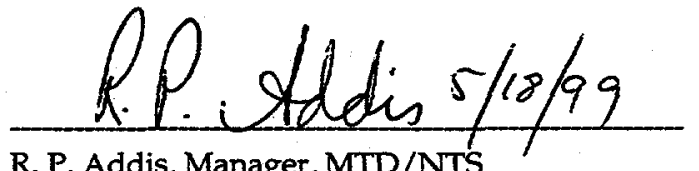

nager, $M$

Westinghouse Savannah River Company

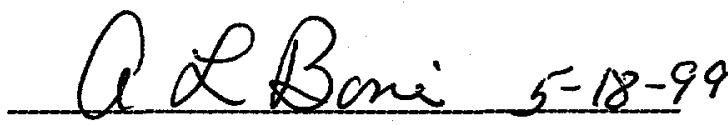

A. L. Boni, Manager, MTD/NTS

Westinghouse Savannah River Company

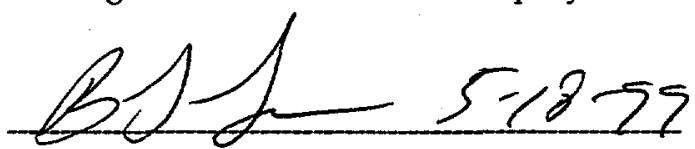

B. L. Lewis, Manager, HLWM/CST Eng. Support Westinghouse Savannah River Company

Prepared for the U.S. Department of Energy under Contract no. DE-AC09-96SR18500 
This page intentionally left blank. 


\title{
Contents
}

\author{
Executive Summary 1 \\ Introduction 2 \\ Data 2 \\ Waste Level Measurements 2 \\ Atmospheric Pressure Measurements 3 \\ Temperature and Humidity Measurements in the Purge Air Stream 4 \\ Model Components 6 \\ Earlier Versions of the Trapped Gas Model 6 \\ Improved Model to Account for Trapped Gas in a Salt-Cake or Sludge Layer 6 \\ Tank Vessel and Non-Gaseous Contents Effects on Waste Level 7 \\ Moisture Condensation/Evaporation 8 \\ Solid-to-Liquid and Liquid-to-Solid Mass Exchange 8 \\ Expansion /Contraction of the Liquid Waste 8 \\ Expansion/Contraction of the Salt-Cake 9 \\ Expansion/Contraction of the Steel Tank 9 \\ Model Implementation 10 \\ Results 11 \\ Model Results for Tank 32H 11 \\ Spectra for Tank 32H 12 \\ Model Results for Tank $36 \mathrm{H} 12$ \\ Spectra for Tank $36 \mathrm{H} 13$ \\ Level Changes Due to Temperature and Moisture Effects 13 \\ Level Changes from Hydrogen Production within the Waste 15 \\ Conclusions 17 \\ Level Changes from Thermal Expansion Effects in Cooling Coils 15 \\ Acknowledgments 18 \\ References 19 \\ Appendix A: Model Development 21 \\ Appendix B: Uncertainty Analysis 28 \\ Appendix C: Salt Solubility Relations and Mass Exchange Equations 32
}




\section{List of Figures}

Figure 1. Measured Waste Level (inches) for Tank 32H for the Period May 23-July 31, 1998. Time is Eastern Daylight Time (EDT) with Seven-Day Periods. 36

Figure 2. $\quad$ Measured Waste Level (inches) for Tank 32H and Inverse Pressure (1/bars) for the Period May 21-June 4, 1998. Time is Eastern Daylight Time (EDT) with Seven-Day Periods. (Solid line is for Level; Dashed line is 1/Pressure). 37

Figure 3. Measured Waste Residual Level for Tank 32H and Inverse Pressure (1/bars) for the Period May 21-31, 1998. Time is Eastern Daylight Time (EDT) with Seven-Day Periods. (Solid line is for Level; Dashed line is 1/Pressure). 38

Figure 4. $\quad$ Spectral Density of Measured Atmospheric Pressure for the Period May 21-31, 1998. Period in Hours. 39

Figure 5. Spectral Density of Measured Residual Level for Tank 32H for the Period May 21-31, 1998. Period in Hours. 40

Figure 6. Measured Waste Residual Level for Tank 32H and Inverse Pressure (1/bars) for the Period June 10-20, 1998. Time is Eastern Daylight Time (EDT) with Seven-Day Periods. (Solid line is for Level; Dashed line is 1/Pressure). 41

Figure 7. Spectral Density of Measured Atmospheric Pressure for the Period June 10-20, 1998. Period in Hours. 42

Figure 8. Spectral Density of Measured Residual Level for Tank 32H for the Period June 10-20, 1998. Period in Hours. 43

Figure 9. Measured Waste Level (inches) for Tank 36H for the Period May 23-July 31, 1998. Time is Eastern Daylight Time (EDT) with Seven-Day Periods. 44

Figure 10. Measured Waste Level (inches) for Tank $36 \mathrm{H}$ and Inverse Pressure (1/bars) for the Period May 21-June 20, 1998. Time is Eastern Daylight Time (EDT) with Seven-Day Periods. (Solid line is for Level; Dashed line is 1/Pressure). 45

Figure 11. Measured Waste Residual Level for Tank 36H and Inverse Pressure (1/bars) for the Period June 3-19, 1998. Time is Eastern Daylight Time (EDT) with Six-Day Periods. (Solid line is for Level; Dashed line is 1/Pressure). 46

Figure 12. Spectral Density of Measured Atmospheric Pressure for the Period June 3-19, 1998. Period in Hours. 47

Figure 13. Spectral Density of Measured Residual Level for Tank 36H for the Period June 3-19, 1998. Period in Hours. 48

Figure 14. Measured Waste Residual Level for Tank $36 \mathrm{H}$ and Inverse Pressure (1/bars) for the Period June 22-July 27, 1998. Time is Eastern Daylight Time (EDT) with Seven-Day Periods. (Solid line is for Level; Dashed line is 1/Pressure). 49

Figure 15. Spectral Density of Measured Atmospheric Pressure for the Period June 22-July 27, 1998. Period in Hours. 50

Figure 16. Spectral Density of Measured Residual Level for Tank 36H for the Period July 22-July 27, 1998. Period in Hours. 51

Figure 17. Time Series of Measured Temperatures (deg. C) for Tanks $32 \mathrm{H}$ and 36H. (Solid Tank $32 \mathrm{H}$ incoming air, light gray dash is Tank $32 \mathrm{H}$ outgoing air, dark gray dash is Tank $36 \mathrm{H}$ incoming air, long gray dash is Tank $36 \mathrm{H}$ outgoing air. 52

Figure 18. Time Series of Measured Relative Humidities (percent) for Tanks $32 \mathrm{H}$ and $36 \mathrm{H}$. (Solid Tank $32 \mathrm{H}$ incoming air, light gray dash is Tank $32 \mathrm{H}$ outgoing air, dark gray dash is Tank $36 \mathrm{H}$ incoming air, long gray dash is Tank $36 \mathrm{H}$ outgoing air. 53

Figure 19. Time Series of Computed evaporation/condensation (inches) for Tanks $32 \mathrm{H}$ and $36 \mathrm{H}$ for the time period June 16-24, 1998. (Solid line is for Tank 32H, light gray dash is for Tank 36H.) 54

Figure 1A. A schematic diagram of a waste tank containing a single gas pocket. 21 


\section{List of Tables}

Table I. Standard deviation of the level measurements from Tanks $32 \mathrm{H}$ and $36 \mathrm{H}$. (Measurements taken every 30 seconds for a 30-minute time period.) 3

Table C1. Table of coefficients for determining the weight percent of $\mathrm{NaNO}_{3}$ and $\mathrm{NaOH}$ by empirical formula. 32

Table C2. $\mathrm{NaOH}$ and $\mathrm{NaNO}_{3}$ molarities for two different solutions. 32

\section{List of Appendices}

Appendix A. Model Development 21

Appendix B. Uncertainty Analysis 28

'Appendix C. Salt Solubility Relations and Mass Exchange Equations 32 


\section{Executive Summary}

This report contains documentation for improvements in a model for predicting the volume of gas bubble retention based on changes in waste level for high-level waste tanks at the Savannah River Site (SRS). The model is based on work by Weber and Smith (1997) in which the waste tank void fraction for a salt tank was estimated using statistical techniques.

The improved model explained here contains separate treatments for estimating the void fraction in salt and sludge tanks. The void fraction calculation in salt tanks contains a correction for gas volume changes due to temperature changes. When solving for a sludge tank's void fraction, the model must attribute waste level changes only to gas expansion/contraction caused by atmospheric pressure. The effect of fluid thermal expansion/contraction on waste level changes in sludge tanks is stronger than the effect of gaseous thermal expansion/contraction since there is much more liquid than gas volume in typical SRS sludge tanks. (In implementing the model for sludge tanks, it is necessary to judiciously choose the time period for which the calculation is made since its accuracy will depend on having statistically homogeneous, steady conditions with (at most) a linear trend in the waste level time series.)

The improvements in the model also account for the fact that trapped gas is confined only to a sludge or salt-cake layer rather than being uniformly distributed throughout the waste (as was the case for the earlier model). The new model is also conveniently implemented through a graphical user interface.

The model incorporating these improvements was used to estimate the void fraction in Tank $32 \mathrm{H}$ (containing sludge) and Tank $36 \mathrm{H}$ (containing salt). For the tanks examined thus far, salt tanks have a larger void fraction than do sludge tanks.

Despite the difficulties in capturing temperature effects on waste level, a separate subroutine of the new model has been coded so that waste level changes caused by temperature changes on the tank vessel and its non-gaseous contents (previously identified by Duignan, 1994) can be computed as a diagnostic tool. The effects identified by Duignan are not included in the model's current void fraction calculation because of large uncertainties in the parameters used to estimate some of the critical expansion/contraction terms. It is possible in the future that gathering tank level data can establish some of the unknown parameters more precisely and that Duignan's effects can be used in a predictive instead of a diagnostic mode.

Model computations were made for High-Level Waste Tanks $32 \mathrm{H}$ (containing sludge) and 36H (containing salt) for the period May 21 through July 31, 1998. Computations for Tank $32 \mathrm{H}$ showed very little trapped gas, i.e., $2.0 \% \pm 5.8 \%$ ( $\pm \%$ 
indicates the upper and lower 95\% confidence limits) between May 23-31 (prior to a transfer) and $-1.5 \% \pm 1.6 \%$ during June 9-19 (after waste was removed from the tank). The negative void fraction has no physical meaning. The fact that the $95 \%$ confidence interval includes zero indicates that the void fraction is essentially zero.

Model results for Tank $36 \mathrm{H}$ showed that its void fraction varied between $15.0-16.3 \%$ $\pm 5 \%$ prior to an inter-tank transfer. The void fraction range after waste was removed from Tank $36 \mathrm{H}$ was $9.5 \% \pm 2.2 \%$ on one occasion and $0.8 \% \pm 1.9 \%$ a few days later. The cause of the first decrease in void fraction may be from settling of the tank solids. There were no transfers of waste between the times when the void fraction decreased from $9.5 \%$ to $0.8 \%$. The cause of the second decrease in void fraction is not clear at this time. These differences in the void fraction estimates from the before and after-transfer periods suggest that trapped gas could have been released.

\section{Introduction}

A Potential Inadequacy in the Safety Analysis (PISA) for the High Level Waste Tanks (WSRC PISA \#NI-HLW-96-014, rev. 2, May. 1997) requires that SRS develop new engineering analyses including a program to investigate the amount of trapped gas in high level waste tanks. Void fraction was successfully modeled for Tank $41 \mathrm{H}$ based on a simple theory using an estimation of the derivative $\mathrm{dh} / \mathrm{dp}$ (the derivative of waste level with respect to pressure) over a period of a few weeks (Weber and Smith, 1997). Success with this method led to the reasonable expectation that the theory could be extended to other tanks in the waste complex, including tanks containing sludge. To test these ideas, hourly waste level measurements were made for Tanks $32 \mathrm{H}$ and $36 \mathrm{H}$, the former containing about 183,000 gallons of sludge and the latter containing about 1,094,000 gallons of salt-cake. During this same time period (May 21 through July 31, 1998) measurements were made to determine the amount of moisture condensation/evaporation in the two tanks as a refinement of the $\mathrm{dh} / \mathrm{dp}$ model.

Data

\section{Waste level Measurements}

Waste level sensors used in the waste tanks provide liquid level to the nearest $1 / 100^{\text {th }}$ of an inch on a digital readout in the H-Area HLW control room. Waste level measurements are taken according to procedure once per day and reported on control room operator round-sheets. In addition, during the period May 21 to July 31,1998 , data for Tanks $32 \mathrm{H}$ and $36 \mathrm{H}$ were recorded each hour on special forms provided by CST Engineering. The entries on these forms comprised an hourly, 72day record for each tank. The waste data entries on these forms were subsequently entered into computer data files for analysis. 
Data for waste level were also taken at 30-second intervals on two occasions to determine the statistical variation in the level measurements for 30-minute time periods for Tanks $32 \mathrm{H}$ and $36 \mathrm{H}$. The standard deviations based on 60 readings each for the tanks on each day are show in Table 1 below.

Table 1. Standard deviation of the level measurements from Tanks $32 \mathrm{H}$ and $36 \mathrm{H}$. (Measurements taken every 30 seconds for a 30-minute time period.)

\begin{tabular}{|l|l|l|}
\hline & $\begin{array}{l}\text { November 11, 1998 } \\
\text { Standard Deviation (in.) }\end{array}$ & $\begin{array}{l}\text { November 12, 1998 } \\
\text { Standard Deviation (in.) }\end{array}$ \\
\hline Tank 32H & 0.0576 & 0.0025 \\
\hline Tank 36H & 0.0330 & 0.0262 \\
\hline
\end{tabular}

The data for the November 11 entry for Tank $32 \mathrm{H}$ was two days following a waste transfer from the tank. The following day's standard deviation was considerably smaller and was statistically different (at the $95 \%$ confidence level) than the data from the previous day. This was undoubtedly due to decay of residual turbulence in the tank contents following the transfer. There was no statistically significant difference in the standard deviations for Tank $36 \mathrm{H}$ between the two days.

The standard deviations mentioned above are used to characterize the error in the digital readout of the waste level measurement of a quiescent tank. The November 12,1998 standard deviations are likely to be the most representative values for the digital readout error for these two tanks.

\section{Atmospheric Pressure Measurements}

Atmospheric pressure measurements are obtained with calibrated sensors at the Savannah River Technology Center's (SRTC) Central Climatology Station near CArea and then transferred electronically into a computer database in 773-A every 15 minutes. The Central Climatology Station is 3 to 4 miles distant from Tanks $32 \mathrm{H}$ and $36 \mathrm{H}$ so that the pressure measurements can be extrapolated to apply at the waste tanks' locations. Pressure measurements are also available at the Bush Field weather station (near Augusta, Georgia) from an Automated Surface Observation System (ASOS).

The difference in elevation between Bush Field and Central Climatology is 92 meters so that a correction, based on this height difference and the hypsometric equation is used to make the two pressure measurements comparable. Small periods of missing data in the Central Climatology Station's pressure record were filled in with heightcorrected National Weather Service (NWS) data from Bush Field. 
The accuracies of the atmospheric pressure sensors at the Central Climatology Station are as follows:

$$
\begin{array}{r}
\text { Rosemont calibration } \pm 0.5 \mathrm{mb}, \\
\text { precision } \pm 0.1 \mathrm{mb}, \\
\text { Mercury Barometer calibration } \pm 0.2 \mathrm{mb}, \\
\text { precision } \pm 0.1 \mathrm{mb},
\end{array}
$$

Two pressure offsets were encountered in the data collection period. On June 18, 1998 , during routine calibration, the Rosemont pressure sensor was replaced with a new sensor. Comparison of the calibration records of the two Rosemont instruments (compared to a mercury barometer at the Central Climatology Site) indicated that the old replaced sensor was offset $+0.4 \mathrm{mb}$ compared to the new sensor.

A second offset occurred on May 29, 1998 when a power outage caused an offset of $+5.8 \mathrm{mb}$ compared with the newer (post-June 18) sensor. This $5.8 \mathrm{mb}$ offset was determined during a side-by-side comparison test of 4 days conducted after June 18, 1998. In summary, maximum consistency of the data was obtained with the following corrections:

$\begin{array}{ll}\text { time period } & \text { correction } \\ \text { prior to May 29 } & -0.4 \mathrm{mb} \\ \text { May 29-June18 } & -5.8 \mathrm{mb} .\end{array}$

These results are documented in a June 23, 1998 memo from R. J. Kurzeja to A. H. Weber.

The operational characteristics of the ASOS are Range: $572.3-1066.7 \mathrm{mb}$, Accuracy: $\pm 0.677 \mathrm{mb}$, Resolution: $0.17 \mathrm{mb}$ (reporting), $0.10 \mathrm{mb}$ (measurement).

\section{Temperature and Humidity Measurements in the Purge Air Stream}

Purge air fans in a typical high-level waste tank force ambient air drawn from around the purge inlet into the tank's headspace and out the tank's exhaust stack. The nominal purge rate for Tank $32 \mathrm{H}$ is $171 \mathrm{scfm}$ and for Tank $36 \mathrm{H}$ is $301 \mathrm{scfm}$. The purge fan operation is sometimes interrupted for various reasons, but the fan remains on most of the time to blow ambient air through the waste tank. Depending on the temperature and moisture conditions inside the tank, this can result in a net atmospheric moisture contribution to the tank liquid level from condensation or evaporation. This condensation/evaporative contribution can be estimated by measuring the atmospheric moisture content of the air prior to entering the tank and before exiting the tank's exhaust stack. 
Temperature and humidity data in the inflow and outflow streams were obtained with four Campbell CS500 temperature/humidity probes and averaged for each hour. The stated accuracy of these probes is $\pm 0.5^{\circ} \mathrm{C}$ (for $20^{\circ} \mathrm{C}-40^{\circ} \mathrm{C}$ ) and $\pm 3 \%$ humidity (10-90\%). Because the purpose of the experiment was to calculate net moisture accumulations, it was decided to improve the results with more precise calibrations under the assumption that the precision (reproducibility) of the sensors is better than their absolute accuracy. To accomplish this, a fifth CS500 probe (standard) was used to conduct side-by-side comparisons with each of the four operational probes. The standard probe was placed next to each operational probe in the same radiation shield and the temperature and humidity allowed to equalize for 10 minutes. The average difference in the last minute was noted and is a measure of the relative differences between the probes. These differences are as follows, all expressed with respect to the standard probe.

ID inflow temp inflow rel. hum. outflow temp outflow rel. hum.

$\begin{array}{lllll}\text { Logger } 2419 & +0.3^{\circ} \mathrm{C} & -4.1 \% & +0.6^{\circ} \mathrm{C} & -4.7 \% \\ \text { Logger } 1919+0.5^{\circ} \mathrm{C} & -2.9 \% & +0.4{ }^{\circ} \mathrm{C} & -3.1 \%\end{array}$

These differences can be used to make slight corrections to the inflow and outflow data. For example, if one uses the inflow sensor for Logger 2419 as our baseline, we should subtract $0.3^{\circ} \mathrm{C}$ from the outflow temperature and add $0.6 \%$ to the relative humidity. One should also subtract $0.2{ }^{\circ} \mathrm{C}$ from the Logger 1919 inflow temperature and $1.2 \%$ from the inflow relative humidity. A subtraction of $0.1^{\circ} \mathrm{C}$ should also be made from the outflow temperature and $1.0 \%$ from the outflow relative humidity.

An additional fact that should be noted is that the probes were located in positions where solar radiation effects could affect the recorded temperatures. For example, the inflow probes were located in radiation shield $\sim 6$ inches above a concrete slab. The probes were also shaded during some parts of the day and in direct sun other times of the day. Since the radiation shields are not completely effective under these conditions, the inflow temperatures could be too high by up to $1^{\circ} \mathrm{C}$. However, the sensor relative humidities are negatively correlated with temperature, and thus the specific humidity should not be significantly affected by the radiation problems. Outflow temperatures could also be affected by radiation since the outflow pipe walls are generally colder than the air temperature. However, outflow rates are high in the exhaust pipes and this should minimize the radiative effects. 


\section{Model Components}

\section{Earlier Versions of the Trapped Gas Model}

The basic form of the trapped gas model is found in Stewart et al. (1996) and Whitney (1995). The estimate of the void fraction $\alpha$ is based on measurements of the atmospheric pressure $\mathrm{p}_{0}$, the waste level $h$, and an estimate of the derivative of the level with respect to pressure $\left(\mathrm{dh} / \mathrm{dp}_{0}\right)$, as follows:

$$
\alpha=\frac{p_{0}}{h}\left(-d h / d p_{0}\right)
$$

A more accurate expression for $\alpha$ was derived by Smith (in Weber and Smith, 1997) in the form

$$
\beta \eta \alpha^{2}+\alpha-\eta\left[\frac{\overline{p_{0}}}{\bar{h}}+\beta\right]=0
$$

from which $\alpha$ is solved using the quadratic formula. Here $\beta=\rho_{1} g / 2$ and $\eta=-\mathrm{dh} / \mathrm{dp} p_{0}$, where $\rho_{1}$ is the liquid density and $g$ is the acceleration of gravity. The symbol $\bar{p}_{0}$ refers to the average atmospheric pressure and $\bar{h}$ refers to the average waste level over the time period of interest. Eq. (2) is more accurate than Eq (1) since it contains second order terms from an expansion that was used to determine the derivative $\mathrm{dh} / \mathrm{dp}_{0}$ (Weber and Smith, 1997).

Smith's 1997 model assumes that the trapped gas is uniformly distributed throughout the total mixture volume and that long-term trends in the waste level can be ignored. Smith's model is implemented by using measurements of pressure, temperature, and level data.

Neither model above takes into account gas bubble release or upward migration during the time period over which they are applied, in fact, both models assume a fixed mass of gas and that the gas is uniformly distributed through the waste volume. Both models should apply in an average sense over the time period which they are applied.

\section{Improved Model to Account for Trapped Gas in a Salt-Cake or Sludge Layer}

During the peer review of this project (Britt, 1999), some reviewers questioned the model assumption about the trapped-gas being uniformly distributed throughout the tank, rather than being confined to a salt-cake or sludge layer. Smith responded 
by deriving another version of the model equations with the assumption that the trapped gas is in a salt-cake or sludge layer with an overlying supernate layer that cannot retain undissolved gas. The result for the void fraction is

$$
\alpha_{s l}=\frac{1}{h_{s}}\left(-\left.\frac{\partial h}{\partial p_{0}}\right|_{T}\right)\left[\frac{p_{0}+\beta\left\{h+(\gamma-1) h_{e}-\left(1-\frac{\gamma}{2}\right) h_{s}\right\}}{1+\left.\beta \frac{\partial h}{\partial p_{0}}\right|_{T}}\right]
$$

where $\alpha_{\mathrm{sl}}=$ the volume fraction of gas in the salt-cake/sludge layer, $\beta=\rho g$, $\rho$ is the average density of the liquid; $h$ is the (time-averaged) total waste thickness including the solid layer containing no gas, the solids layer containing gas, and the supernate layer; $h_{e}=$ thickness of the sludge or salt layer that does not contain gas; $h_{s}$ $=$ thickness of the salt or sludge layer containing gas; $\gamma=\rho_{s} / \rho ; \rho_{s}$ is the density of the sludge or salt in the trapped gas layer; $p_{0}$ is the (time-averaged) ambient pressure; and $T$ is the waste temperature.

Smith also derived an expression for the void fraction, which included the effect of gas expansion/contraction due to sludge/salt temperature changes. These results as well as the derivation of the equation for void fraction above are contained in Appendix $\mathrm{A}$ in this report. A derivation of the uncertainty as expressed by the variance of $\alpha$ due to the following measured variables: $\rho_{s}, h_{e}, h_{s}, \rho, T_{t}, P_{t}$, and $h_{t}$ is contained in Appendix B of this report.

[The following six sections (ending with Expansion/Contraction of the Steel Tank) represent a discussion of effects on tank waste level that are not included in the current implementation of the model except as user-selectable diagnostic quantities. To make the discussion complete they are included here and could be used in future versions of the model when some of the important waste properties can be better estimated.]

\section{Tank Vessel and Non-Gaseous Contents Effect on Waste Level}

The tank vessel and non-gaseous content effects on the waste level were identified and modeled by Duignan (1994). Six of the effects modeled by Duignan have been included as an optional calculation in the model being discussed here:

(1) condensation/evaporation of water into/from the supernate due to purge air flow,

(2) condensation at the purge gas condenser, 
(3) solid-to-liquid and liquid-to-solid mass exchange,

(4) expansion/contraction of the salt-cake,

(5) expansion/contraction of the liquid waste,

(6) expansion/contraction of the steel tank.

\section{Moisture Condensation/Evaporation}

Given temperature and humidity measurements, the net condensation or evaporation of water can be computed by determining the mixing ratio in the entering and departing air streams. $\mathrm{M}_{\mathrm{H} 2 \mathrm{O}}=\left(\mathrm{m}_{\mathrm{in}}-\mathrm{m}_{\text {out }}\right) \mathrm{M}_{\mathrm{dry} \text { air }}$, where $\mathrm{m}_{\mathrm{in}}$ is the mixing ratio (meteorological definition: mass of $\mathrm{H}_{2} \mathrm{O}$ per unit mass of dry air) of the entering air stream, $\mathrm{m}_{\text {out }}$ is the mixing ratio of the departing air stream, and $\mathrm{M}_{\mathrm{dry} \text { air }}$ is the mass of dry air passing through the system during the time period of interest.

\section{Solid-to-Liquid and Liquid-to-Solid Mass Exchange}

This effect applies to salt-cake but not to sludge. Solid-to-liquid and liquid-to-solid mass exchange is modeled by accounting for mass that dissolves from the solid into the liquid or precipitates from the liquid to the solid as the solution temperature changes. Application of this model assumes that the solution remains saturated in response to temperature changes. The change in waste level can be calculated from the equation

$$
\Delta \mathrm{H}=\left[\left(\mathrm{H}_{\mathrm{w}}-\mathrm{H}_{\mathrm{sc}}\right) \phi_{1}+\mathrm{H}_{\mathrm{sc}} \chi_{\mathrm{sc}} \phi_{2}\right]\left[1-\rho_{\mathrm{sup}} / \rho_{\mathrm{sc}}\right]
$$

where $\Delta \mathrm{H}$ is the change in waste level, $\mathrm{H}_{\mathrm{w}}$ is the height of the waste, $\mathrm{H}_{\mathrm{sc}}$ is the height of salt-cake above the bottom of the tank wall, and $\chi_{s c}$ is the volume fraction of liquid in the salt-cake. The functions $\phi_{1}$ and $\phi_{2}$ are given by

$\phi_{1}=\left[\frac{\omega t_{2}-\omega t_{1}}{1-\omega t_{2}}\right]$ supernate for the supernate and $\phi_{2}=\left[\frac{\omega t_{2}-\omega t_{1}}{1-\omega t_{2}}\right]_{\text {saltcake }}$ for the liquid

solution in the salt-cake. $\omega t_{1}$ is the weight fraction of salt in solution at temperature $\mathrm{T}_{1}$ and $\omega t_{2}$ is the weight fraction of salt in solution at $\mathrm{T}_{2}$, which are determined from Duignan's (1994) Tables 5a-e. A derivation of this equation and more complete description of its application are provided in Appendix $C$ of this report.

\section{Expansion/Contraction of the Liquid Waste}

Expansion/contraction of the liquid waste is modeled by using

$$
\Delta \mathrm{H}=\mathrm{H}\left[\frac{\chi_{1} \Delta \rho_{1}}{\rho_{1} \Delta T_{1}}+\frac{\chi_{2} \Delta \rho_{2}}{\rho_{2} \Delta T_{2}}\right] \Delta T
$$


where $\Delta \mathrm{H}$ is the change in waste level. Here, subscript 1 refers to $\mathrm{NaNO}_{2}+\mathrm{NaNO}_{3}$ and subscript 2 refers to $\mathrm{NaOH}$.

This equation is applied twice with

$$
\begin{aligned}
& \mathrm{H}=\left(\mathrm{H}_{\mathrm{w}}-\mathrm{H}_{\mathrm{sc}}\right) \text { to account for the liquid above the salt-cake and } \\
& \mathrm{H}=\mathrm{H}_{\mathrm{sc}} \chi_{\mathrm{sc}} \text { to account for the liquid within the salt-cake. }
\end{aligned}
$$

$\mathrm{H}_{\mathrm{w}}$ is the total height of the waste above the bottom of the tank, $\mathrm{H}_{\mathrm{sc}}$ is the height of the salt-cake, and $\chi_{s c}$ is the volume fraction of liquid in the salt-cake. For either calculation; $\chi_{1}$ is the combined mass fraction of $\mathrm{NaNO}_{2}$ and $\mathrm{NaNO}_{3}, \chi_{2}$ is the mass fraction of the $\mathrm{NaOH}$. The densities $\rho_{1}$ and $\rho_{2}$ and the changes in density with respect to temperature $\Delta \rho_{1}$ and $\Delta \rho_{2}$ for each component are calculated from Tables 6 and 7 in Duignan's report. The term $\Delta \mathrm{T}$ is the temperature change of the waste in the time period of interest.

\section{Expansion/Contraction of the Salt-cake}

Expansion/contraction of the salt-cake is modeled by using the linear expansion coefficient $c_{0}$ for the salt-cake. The change in waste level is calculated as

$$
\Delta \mathrm{H}=\left(1-\chi_{\mathrm{sc}}\right) \mathrm{H}_{\mathrm{sc}} \mathrm{c}_{0} \Delta \mathrm{T} ; \mathrm{c}_{0}=1.02 \times 10^{-4}\left({ }^{\circ} \mathrm{C}^{-1}\right)
$$

where $\Delta \mathrm{H}$ is the change in waste level, $\chi_{s c}$ is the volume fraction of liquid in the saltcake, $\mathrm{H}_{\mathrm{sc}}$ is the height of salt-cake above the bottom of the tank, and $\Delta \mathrm{T}$ is the temperature change of the salt-cake in the time period of interest.

\section{Expansion/Contraction of the Steel Tank}

Expansion/contraction of the steel tank is modeled using the linear expansion coefficients for steel and assuming that the area coefficient of expansion is twice the linear coefficient. The change in waste level is then calculated from

$$
\Delta \mathrm{H}=-\mathrm{H}_{w}\left[2\left(\mathrm{~b}_{0}+\mathrm{b}_{1} \mathrm{~T}\right)\right] \Delta \mathrm{T} ; \mathrm{b}_{0}=1.08 \times 10^{-5}\left({ }^{\circ} \mathrm{C}^{-1}\right), \mathrm{b}_{1}=7.70 \times 10^{-9}\left({ }^{\circ} \mathrm{C}^{-2}\right)
$$

where $\Delta \mathrm{H}$ is the change in waste level, $\mathrm{H}_{\mathrm{w}}$ is the total height of the waste above the bottom of the tank, $T$ is the temperature of the tank wall, and $\Delta T$ is the temperature change of the tank wall in the time period of interest. (It should be noted that an increase in the tank volume due to increasing temperatures would cause the waste level to fall.) The contribution to the overall change in waste level from expansion or contraction of the steel tank is very small. 


\section{Model Implementation [Refer to Appendix A for the Model Derivation and Discussion]}

The model has been coded and is implemented under a graphical user interface within the $S A S \otimes$ system. The advantage of this system is that it is user-friendly and simple to implement. The graphical user interface is operated as described by Harvel (1999). After the software is launched the user chooses a tank identification number (which automatically determines whether the tank contains salt, sludge, or a mixture of both salt and sludge), the thickness of the solids layer containing gas, the thickness of the solids layer containing no gas, and the time period of interest. A command is then issued to run the model. The model takes one of two branches depending on whether the waste tank contains sludge or salt. The branch for salt-containing tanks solves Eq. (A26) in Appendix A (that accounts for temperature expansion of gas bubbles in the salt-cake). For tanks that contain sludge, in order to remove the temperature expansion/contraction of the non-gaseous components of waste, a linear trend of waste level is removed from the original data set of waste level and time. Then the model uses the waste residual level (with the trend removed) and the pressure data to determine the derivative $\mathrm{dh} / \mathrm{dp}$. The value of this derivative is then used in Eq. (A10) to determine the void fraction. The user is allowed to choose either the salt or the sludge path when dealing with mixed tanks. At this time there is no model which can account for both salt and sludge in the same waste tank. However, a hybrid model incorporating both species could be addressed in the future.

When using the model to determine the void fraction of sludge tanks, it is important to choose a portion of the time series when the waste level residuals pattern shows no cycles, trends, or major outliers, i.e., the pattern of waste level residuals should be relatively homogeneous along the time axis. In order to accomplish this, the model user is shown plots that allow the residual patterns to be examined. Generally a period of several days to a few weeks should be chosen for analysis. If the residual pattern appears to be unacceptable, i.e., it contains cycles, trends, or outliers, then a new time period should be chosen, perhaps a smaller segment of the original time series.

The meaning of cycles, trends, or major outliers in the time series of residuals is either (1) an indication that the amount of trapped gas is changing, or (2) that. temperature expansion/contraction effects are interfering with the calculation of the derivative $\mathrm{dh} / \mathrm{dp}$. The statistical term "confounding" is used in this instance, which means that the waste level changes caused by temperature are improperly being attributed to atmospheric pressure. Shine (1999) showed that supernate temperature changes cause a first order effect in the ordinary least squares regression model and therefore confound the calculation of the derivative 
$\mathrm{dh} / \mathrm{dp}$. The difficulty is that one has to be extremely careful in removing this confounding effect to enable the derivative $\mathrm{dh} / \mathrm{dp}$ to be calculated accurately. Several trials with the model seem to indicate that the best choice is to fit a linear regression model containing time and pressure as independent variables and tank waste level as the dependent variable. This is equivalent to removing a linear trend in the waste level (and consequently, the temperature expansion/contraction of the non-gaseous components of waste) over the time series and determining the derivative $\mathrm{dh} / \mathrm{dp}$ using the residuals of waste level.

\section{Results}

\section{Model Results for Tank 32H}

High-level waste Tank $32 \mathrm{H}$ is a Type IIIA "high-heat receipt tank" containing about 293.0 inches $(1,029,623 \mathrm{gal})$ of waste and 52.1 inches $(182,871 \mathrm{gal})$ of sludge for a total fill level of 345.4 inches in June 1998. In August 1998 the tank contained about 217.5 inches $(763,425 \mathrm{gal})$ of waste and 52.1 inches $(182,871 \mathrm{gal})$ of sludge. The total radiolytic heating rate in May was about $369,602 \mathrm{BTU} / \mathrm{hr}$ and the calculated steady hydrogen generation rate is about $2.60 \mathrm{ft}^{3} / \mathrm{hr}$. The measured hydrogen generation rate is $0.5 \mathrm{ft}^{3} / \mathrm{hr}$, which is about five times lower than the calculated rate (Hester, 1998a). (The reason that the calculated hydrogen generation rate differs from the actual rate is that the calculated rate uses very conservative assumptions.)

The hydrogen and associated gases generated from radiolytic decomposition are either dissolved in the liquid, reside in trapped bubbles, or escape the mixture either through molecular diffusion, convection currents, or bubble migration. Since the material properties of the sludge can vary with time, the actual amount of trapped gas in the form of bubbles (expressed as the void fraction) might be expected to vary by several percent.

The Tank 32H waste level is plotted in Fig. 1 . The June $4 \& 20$, and July 11, 1998 waste level changes were due to planned inter-tank waste transfers. A more detailed view of the waste level is shown in Fig. 2 as a solid line for the period May 21 - June 4, 1998 (just as the first transfer began), superimposed on reciprocal-pressure data (dashed line). The figure shows that the fluctuations of reciprocal-pressure and waste level are not correlated as they were for Tank $41 \mathrm{H}$ (Weber and Smith, 1997) as would be expected if Tank $32 \mathrm{H}$ contains trapped gas. The linear trend in the data through May 31 is very likely due to the normal cooling of the tanks being interrupted. (Numerous refrigeration coils throughout the tank maintain cooling.) Assuming the waste behaved like water and taking into account the thermal expansion, Hester and Peterson (1998) closely approximated the linear trend of the waste level during the period ending on May 31. 
Application of the Smith-Weber trapped-gas model to the linear trend between May 23 and 31 gives a void fraction of $2 \% \pm 5.8 \%$. Application of the model for the periods June $9-19$ (after a transfer) gives $-1.5 \% \pm 1.6 \%$. Application of the model for the period July $14-30$ gives $-6.7 \% \pm 7.1 \%$. All these results include zero within the $95 \%$ confidence interval and the negative numbers have no physical significance. Our conclusion is that Tank 32H's void fraction is essentially zero.

\section{Spectra for Tank $32 \mathrm{H}$}

To further strengthen the conclusion that there is no trapped gas in Tank $32 \mathrm{H}$, the power spectra for the reciprocal-pressure and de-trended tank level were computed. The (de-trended) level and inverse-pressure data are shown in Fig. 3 for the period May 21-31, 1998, and the level and pressure spectra are shown in Figs. 4 \& 5. The pressure spectrum (Fig. 4) shows the spectral maxima due to atmospheric tides at 12 and 24-hour periods similar to those found for Tank 41H (Weber and Smith, 1997). The level spectrum shown in Fig. 5, contains a broad, flat peak at 24-hours but no peak at 12-hours. The broad, flat peak at 24-hours in the level-spectrum is very likely due to diurnal temperature changes. The absence of the spectral peak corresponding to a 12 -hour atmospheric tide is evidence that Tank $32 \mathrm{H}$ contains essentially no trapped gas above the threshold of detectability.

The spectra were examined for the period immediately following Tank $32 \mathrm{H}$ 's first waste transfer (June 10-20, 1998). The results (shown in Figs. 6, 7, \& 8) were almost identical, i.e., the level-spectrum contained small, flat, 24-hour maxima, but no $12-$ hour peak.

\section{Model Results for Tank 36H}

High-level waste Tank $36 \mathrm{H}$ is a Type IIIA "high-heat salt-drop tank" initially containing about 53.3 inches $(183,595 \mathrm{gal})$ of free supernate and 311.8 inches $(1,094,418$ gal $)$ of salt for a total fill level of 365.1 inches. The total radiolytic heating rate is about $187,484 \mathrm{BTU} / \mathrm{hr}$ and the calculated hydrogen generation rate is 0.72 $\mathrm{ft}^{3} / \mathrm{hr}$ with an averaged measured rate of $0.04-0.32 \mathrm{ft}^{3} / \mathrm{hr}$. Hydrogen measurements showed long periods of zero release punctuated by occasional "burps" (Hester, 1998a). As with Tank 32H, the hydrogen and associated gases from radiolytic decomposition equilibrate with a portion staying dissolved in the liquid, a portion forming trapped bubbles, and the remaining portion escaping the mixture by molecular diffusion, convection currents, or bubble migration. Thus the actual amount of trapped gas in saltcake might be expected to vary over a range of several percent, depending on perturbations to the contents (such as waste transfers, sparging, atmospheric pressure changes, etc.) 
Tank $36 \mathrm{H}^{\prime}$ s waste level is plotted in Fig. 9. The June 20 waste-level change was a result of a planned inter-tank waste transfer to Tank $32 \mathrm{H}$. A more detailed view of the waste level is shown in Fig. 10 for the period May 21 to June 20, 1998 (just prior to the waste transfer), superimposed on reciprocal-pressure data. The curves for the waste level and reciprocal-pressure follow one other (except for the first ten days) as would be expected if trapped gas were contained in Tank $36 \mathrm{H}$. Application of the trapped-gas model to the entire period May 21 to June 20 gives a void fraction of $10.1 \% \pm 2.2 \%$. Strictly speaking the Smith-Weber model should be applied to a linear trend region of the data, but it is instructive to compare these results with the strict application of the model.

Applying the model to two intervals of time containing linear trends during the pretransfer period, i.e., June $6-9$ gives $15.0 \% \pm 5.0 \%$ and for June $10-15$ gives $16.3 \% \pm$ $5.4 \%$. Applying the model to two linear trend regions of the data during the posttransfer period, June $23-J u l y ~ 1$ gives $9.5 \% \pm 2.2 \%$ and July $7-19$ gives $0.8 \% \pm 1.9 \%$. The cause of the first decrease in void fraction could be from settling of the tank solids. The cause of the second decrease from $9.5 \%$ to $0.8 \%$ is not understood at this time. These results suggest that trapped gas could have been released on these two occasions.

It was difficult to determine quiescent periods of several days after the transfer of waste from Tank $36 \mathrm{H}$ when the model could be applied with confidence. Floating "salt-bergs" (pieces of salt-cake buoyant enough to float on the surface of the supernate) seemed to occasionally confound the level measurement apparatus. The high radiolytic heat load of the tank (a factor of seven higher than that for Tank $41 \mathrm{H}$ which was modeled by Weber and Smith in 1997) made gas production a much more active process than for other salt tanks in the waste complex.

\section{Spectra for Tank $36 \mathrm{H}$}

Spectra for the pre-transfer period from June 3-19, 1998 show the 12-hour spectral peak that would be expected in a waste tank with trapped gases (Figs. 11-13). Spectra for the post-transfer period from June 22-27 show no spectral peak corresponding the 12-hour period as would be expected in a waste tank with little or no trapped gases (Figs. 14-16).

\section{Level Changes Due to Temperature and Moisture Effects}

Waste level changes due to mass exchange, temperature, and moisture effects were modeled in Duignan's (1994) study and characterized as either reversible or irreversible. Error estimates were also provided for the different model components. Each effect on level is either important on a long-term basis (months) or a short term basis (days) as indicated in the parentheses below. 
Duignan examined level changes in a tank containing salt-cake (Tank $41 \mathrm{H}$ ) over a period of about 400 days. The range of Tank $41 \mathrm{H}$ level changes over the study time were

1) $0.0-0.6$ inches $/ 100$ days (uncertainty $40 \%$ ) for evaporation into the purge gas stream (irreversible),

2) $0.0-0.6$ inches $/ 100$ days (uncertainty $40 \%$ ) for moisture condensation at the condenser coil (irreversible),

3) $0.0-2.0$ inches $/ 100$ days (uncertainty $60 \%$ ) for solid/liquid mass exchange (can be either reversible or irreversible),

4) $0.0-1.00$ inches $/ 100$ days (uncertainties, $15 \%$ for liquid $\& 25 \%$ for solid) for saltcake density changes (reversible),

5) $0.0-1.00$ inches $/ 100$ days (uncertainties, $15 \%$ for liquid \& $25 \%$ for solid) for liquid density changes (reversible),

6) 0.0 inches / 400 days (uncertainty $20 \%$ ) for expansion of the steel tank shell (reversible).

It should be noted that although effect \#3 above is the largest, Duignan showed that it is subject to a larger uncertainty than the remaining effects. Uncertainties for the various terms can be found in Duignan's report.

For the current studies of Tank $32 \mathrm{H}$ and $36 \mathrm{H}$, evaporation and condensation of water vapor were computed from measurements of temperature and humidity at the purge air inlet and exhaust described earlier. Plots made each week as the temperature and humidity data were being collected show the periods when the purge fan (forcing ambient air into the tanks) was on and off. The temperatures and humidities for Tanks 32 and 36 for the period June 16-24 are shown in Figs. 17 and 18. Figure 19 shows that Tank $32 \mathrm{H}$ experienced a net evaporative loss, while Tank $36 \mathrm{H}$ experienced a net condensation gain over the period.

The rate of moisture evaporation was in the range $0.005-0.012$ inches/day ( 0.5 to 1.2 inches / 100 days) in Tank 32H. The actual total evaporation in Tank $32 \mathrm{H}$ over 100 days of obtaining data was about 0.6 inches. The rate of moisture condensation was in the range $0.002-0.005$ inches/day $(0.2$ to 0.5 inches $/ 100$ days) in Tank $36 \mathrm{H}$. Both numbers compare well with Duignan's findings.

These rates varied according to atmospheric and tank conditions over the 72-day period of data acquisition. The actual total condensation of water vapor in Tank $36 \mathrm{H}$ over 100 days of obtaining data was about 0.15 inches. The contrasting behavior of the two tanks, i.e., moisture evaporation in Tank $32 \mathrm{H}$ and condensation in Tank $36 \mathrm{H}$, is probably caused by Tank $36 \mathrm{H}$ having a high $\mathrm{OH}^{-}$concentration; whereas Tank $32 \mathrm{H}$ has a relatively low $\mathrm{OH}^{-}$level. (The improved model containing the 
SAS®AUTOREG procedure is able to ignore these kind of relatively long-term trends.)

For future modeling applications over a typically short (six weeks or less) time periods, it is likely that a method of estimating the evaporation and condensation can be found that will eliminate the need for onsite measurements. It should be noted that the measured moisture evaporation/condensation term effect was quite small in these cases compared with the other effects on waste level change.

\section{Level Changes from Hydrogen Production within the Waste}

Radiolytic production of hydrogen, etc. is also taking place in the waste tanks. To determine the effect on tank waste level, a typical gas production rate of $7.68 \mathrm{ft}^{3} /$ day was used. This amount of gas production in Tank $36 \mathrm{H}$ with a volume of $1.2836 \times 10^{6}$ gallons $\left(171,590 \mathrm{ft}^{3}\right)$ would amount to $0.0224 \%$ of the total volume and a change in level of 0.0109 inches in a period of 5 days (a period representative of the model calculations in this report). It is unlikely that the hydrogen production is felt directly and continuously as an increase in waste level since the waste is in a quasiequilibrium state. In this state there are periodic releases of groups of trapped bubbles or "burps" (Hester, 1998c). Dissolved hydrogen gas escapes by molecular diffusion to the head-space volume from the topmost layer of waste in the tanks.

\section{Level Changes from Thermal Expansion Effects in Cooling Coils}

Each of the waste tanks contains an assembly of cooling coils where cold water is circulated to remove radiolytic heat generated by the waste material. For various reasons, the cooling water circulation in the coils may be turned off and on. The impact on liquid level from the subsequent expansion or contraction of the cooling coils was estimated using nominal values for system parameters. While the exact configuration of the cooling coils varies with the type of waste tank, the nominal analysis shows that any effect from size changes in the cooling coils can be neglected when calculating the liquid level.

The following parameter values were assumed to apply for the nominal analysis:

Number of tubes 1000

Diameter of tube 2.5 inches

Material of construction 304L stainless steel

Thermal expansion coefficient $(\boldsymbol{\beta})$ $9.6 \times 10^{-6} \mathrm{in} / \mathrm{in}^{-} \mathrm{F}$ 
Level calibration of waste tank $3510 \mathrm{gal} / \mathrm{in}$

The 304L stainless steel was chosen as the material type since it has a relatively large thermal expansion coefficient. From the response of the tank level to added waste volume, the cross-sectional area of liquid in the tank is estimated to be:

$$
A_{\text {liq }}=\frac{3510 \mathrm{gal}}{\text { in }} \frac{1 \mathrm{ft}^{3}}{7.48 \mathrm{gal}}\left(\frac{12 \mathrm{in}}{\mathrm{ft}}\right)^{3}=8.11 \times 10^{5} \mathrm{in}^{2}
$$

The total area of the cooling coils is:

$$
A_{\text {ubes }}=1000 \frac{\pi(2.5)^{2}}{4}=4.91 \times 10^{3} \mathrm{in}^{2} .
$$

The cooling coils then occupy slightly more than $0.6 \%$ of the total cross-sectional area in the waste tank.

Assuming that the area expansion for the cooling tubes is twice the linear expansion, we estimate the change in area from a change in temperature as:

$$
\frac{1}{A_{\text {tubes }}} \frac{d A_{\text {tubes }}}{d T}=2 \beta
$$

Then using the parameter values shown above, the change in area in square inches is on the order of:

$$
\Delta A_{\text {tubes }}=2\left(9.6 \times 10^{-6}\right)\left(4.91 \times 10^{3}\right) \Delta T=0.0943 \Delta T \text {. }
$$

Assuming that the liquid volume remains constant while the cooling coils experience a change in area, the level response can be calculated as:

$$
\Delta h=h \frac{\Delta A}{A} .
$$

Then, at a tank level of 360 inches, with a temperature change of $100^{\circ} \mathrm{F}$, the change in liquid level would be

$$
\Delta h=360 \frac{9.43}{8.11 \times 10^{5}}=0.0042 \text { in } .
$$


A level change of less than 0.01 inch is within the error of the tank level measurements. This level change is also within the uncertainty of the level estimation methods and can therefore be neglected.

\section{Conclusions}

Application of the Smith-Weber trapped-gas model to Tank $32 \mathrm{H}$ between May 21 and 31 gives a void fraction of essentially zero. The absence of a spectral peak corresponding to the 12-hour atmospheric tide is added evidence that Tank $32 \mathrm{H}$ contains essentially no trapped gas.

Application of the model to Tank $36 \mathrm{H}$ to two intervals of time prior to an inter-tank waste transfer gives a void fraction estimate in the range $15.0-16.3 \%$. The presence of a spectral peak corresponding to the 12 -hour atmospheric tide during this period is evidence that Tank $36 \mathrm{H}$ contains trapped gas. Application of the model to two periods after the inter-tank waste transfer gives void fraction estimates of $9.5 \%$ and $0.8 \%$. The difference between these estimates seems to indicate that gas was released in amounts of $7 \%$ on one occasion and $8.7 \%$ on another. The spectral peak corresponding to the 12-hour atmospheric tide is absent after the inter-tank waste transfer. This suggests that there is little trapped gas after the transfer and that Tank $36 \mathrm{H}$ released trapped gas during and/or after the tank transfer. The reasons for the first gas release may have been settling of the solids within the tank. The reasons for the second release are not clear.

The rate of moisture evaporation was approximately $0.005-0.012$ inches / day $(0.5$ to 1.2 inches $/ 100$ days) in Tank $32 \mathrm{H}$. The rate of moisture condensation was approximately $0.002-0.005$ inches / day ( 0.2 to 0.5 inches $/ 100$ days) in Tank $36 \mathrm{H}$. The most likely reason for these differences is that Tank $36 \mathrm{H}$ contains a much higher $\mathrm{OH}^{-}$concentration, which reduces water vapor pressure.

The atmospheric moisture condensation and evaporation terms are usually second order terms unless the time span is on the order of several days or months. The remaining terms for waste level changes due to temperature and moisture will normally be second order for time spans of a few days, as long as there are no perturbations to the system; the possible exception is the solid/liquid mass exchange which has a large uncertainty of estimation. The moisture evaporation/condensation terms is left as an option in the computer model since the data needed to calculate these terms are not normally available.

The cooling coils thermal expansion effect is a second-order term that need not be included in a waste level model. 
The improved model containing terms for estimating the temperature effect on trapped gas in salt tanks (but not the temperature effects identified by Duignan, 1994) and for taking account that trapped gas is contained only within the solids layer of the waste was used to make these calculations.

\section{Acknowledgements}

The work performed for this project was funded by the U.S. Department of Energy under Contract DE-AC09-89SR18035. The authors wish to thank J. R. Hester, Jr., for his help and direction over the course of this project. 


\section{References}

Britt, T. E., 1999: Peer Review of Gas Bubble Retention Modeling for High-Level Waste Tanks. Inter-Office Memorandum HLW-STE-99-0145, Rev. 0.

Duignan, M. R., 1994: Enhanced Waste Tank Level Model (U), Savannah River Technology Center, Aiken, South Carolina, 29808, WSRC-TR-94-0142, Task No. 93-042-0, 54pp.

Harvel, C. D., 1999: Users Guide for the High Level Waste Applications System(U), SRT-SCS-99-012, April 20, 1999, 19pp.

Hester, J. R. 1998a: cc:Mail communication on the hydrogen generation rates in Tanks $32 \mathrm{H}$ and $36 \mathrm{H}$.

Hester, J. R. 1998b: cc:Mail communication on the cause of evaporation and condensation in Tanks $32 \mathrm{H}$ and $36 \mathrm{H}$.

Hester, J. R. 1998c: cc:Mail communication on the evolution of hydrogen in Tanks $32 \mathrm{H}$ and $36 \mathrm{H}$.

Hester, J. R. and R. A. Peterson, 1998: Calculation sheet on the rate of level change due to liquid waste expansion.

Kurzeja, R. J., 1998: Memorandum on Pressure Measurements at High-Level Waste Tanks $32 \mathrm{H}$ and $36 \mathrm{H}$.

Kurzeja, R. J. and A. H. Weber, 1993: Atmospheric Pressure Fluctuations and Oxygen Enrichment in Waste Tanks. WSRC-TR-93-232. Westinghouse Savannah River Company, Savannah River Technology Center, Aiken, SC 29808.

SAS, 1993: SAS/ETS User's Guide, Version 6, Second Edition. SAS Institute Inc, Cary, NC. 1022 pp.

Shine, E. P., 1999: Recommendations for the Statistical Estimation of the Change in Tank Level due to a Change in Barometric Pressure, SRT-SCS-99026, May 4, 1999, 12pp.

Stewart, C. D., M. E. Brewster, P. A. Gauglitz, L. A. Mahoney, P. A. Meyer, K. P. Recknagle, and H. C. Reid, 1996: Gas Retention and Release Behavior in Hanford Single-Shell Waste Tanks, PNNL-11391, UC-2030, Pacific Northwest National Laboratory, Richland, Washington. 
Weber, A. H. and F. G. Smith, 1997: Atmospheric Pressure Effect of Retained Gas in High Level Waste (U). WSRC-TR-97-0191, Westinghouse Savannah River Company, Savannah River Site, Aiken, SC 29808.

Whitney, P. D., 1995: Screening the Hanford Tanks for Trapped Gas. PNL-10821, Pacific Northwest National Laboratory, Richland, Washington.

WSRC PISA \#NI-HLW-96-014 (rev. 1, Nov. 1996): Potential Inadequacy in the Safety Analyses: Potential for the Release of Hydrogen as a Result of Waste Tank Agitation. 


\section{Appendix A: Model Development}

The previous model of gas entrained in a waste tank as developed by Weber and Smith treats the gas as if it is distributed throughout the entire liquid volume. This model is therefore more correctly a model of dissolved gas in the tank liquid volume. The revised model presented below treats the gas as if it is uniformly distributed only within the saltcake or sludge layer in the waste tank. The model treats gas volume changes from variations in pressure and temperature. A schematic diagram of a waste tank containing a single gas pocket is illustrated in Figure 1A below. We assume that trapped gas is uniformly distributed throughout some part of the salt-cake or sludge layer. This model accounts for the presence of a top layer in the sludge or salt-cake that does not contain gas. We also assume that there is some level of supernate liquid above the solid layer. Some of the nomenclature used in the model development is:
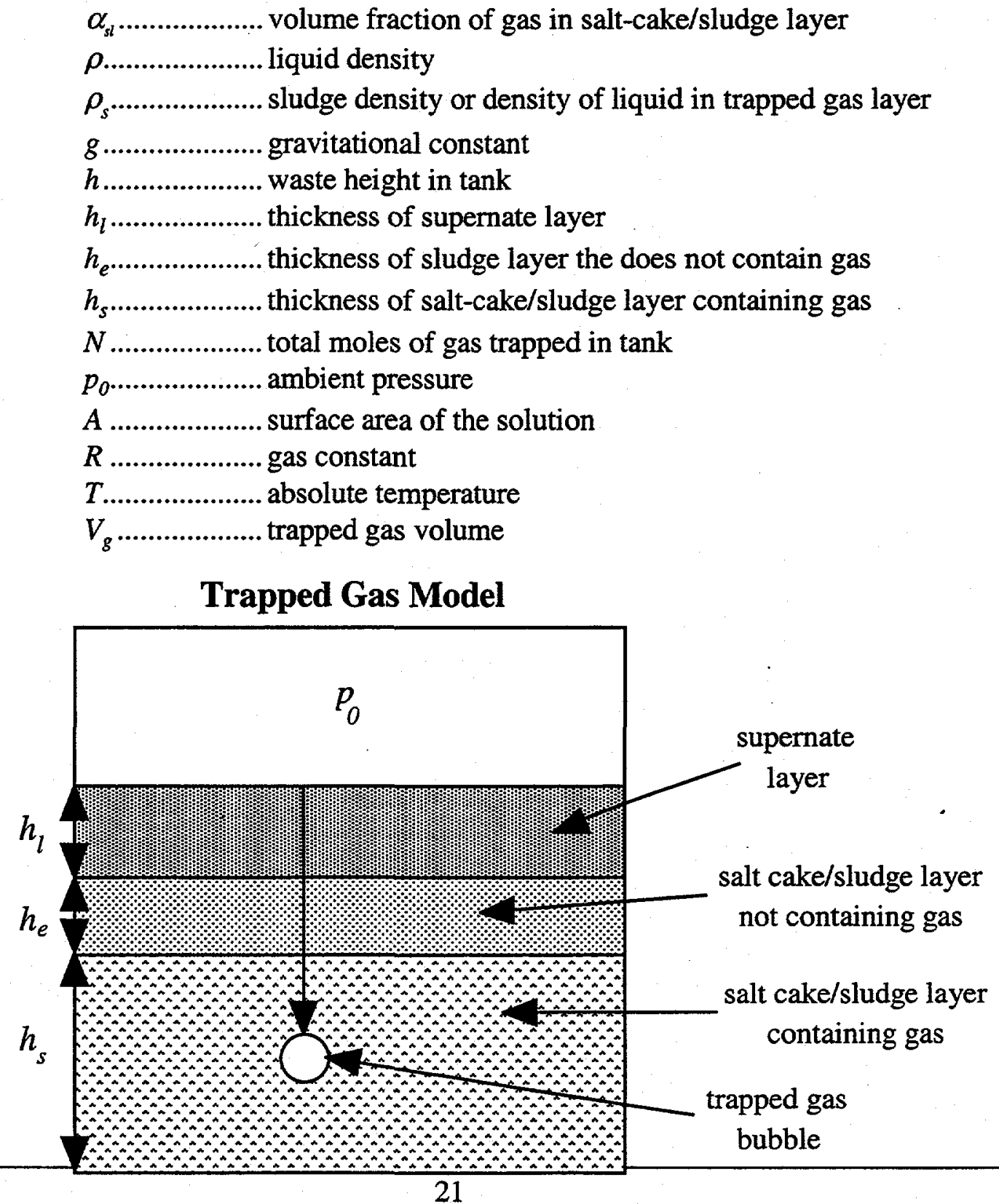
Assuming a uniform distribution of the gas, the average pressure on gas trapped within the salt-cake or sludge layer is:

$$
\begin{aligned}
p_{g} & =p_{0}+\rho g h_{l}+\rho_{s} g h_{e}+\frac{1}{2} \rho_{s} g h_{s} \\
& =p_{0}+\rho g\left[h_{l}+\frac{\rho_{s}}{\rho}\left(h_{e}+\frac{h_{s}}{2}\right)\right] .
\end{aligned}
$$

In writing Eq. (A1), we assume that the trapped gas forms a distinct phase that is separate from the liquid and solids. Therefore, the density used to calculate the pressure on the gas is that of the liquid alone and is not adjusted to account for the presence of the gas. We also account for the possibility of a difference in density between the liquid in the supernate $(\rho)$ and that in the trapped gas layer $\left(\rho_{s}\right)$. By assuming ideal gas behavior, the volume of trapped gas can be calculated from the equation

$$
p_{g} V_{g}=N R T \text {. }
$$

Let $\alpha$ equal the volume fraction of trapped gas in the salt-cake/sludge layer in the waste tank. Then the total volume of trapped gas is given by

$$
V_{g}=\alpha_{s l} A h_{s}=\frac{N R T}{p_{0}+\beta\left[h_{l}+\gamma\left(h_{e}+\frac{1}{2} h_{s}\right)\right]},
$$

where the parameters $\beta=\rho g$ and $\gamma=\rho_{s} / \rho$ have been introduced to simplify the notation.

Assuming that there is always a layer of supernate on top of the salt-cake/sludge layer, a change in the volume of trapped gas will produce an equal change in the volume of the supernate layer. That is, we assume that the trapped gas displaces liquid from the layer and that the salt-cake/sludge layer thickness remains constant. In equation form, we have

$$
\Delta V_{g}=\Delta V_{l}=A \Delta h_{l} .
$$

Differentiating Eq. (A4) while applying Eq. (A3) for $V_{g}$ leads to the relationship: 


$$
\left.A \frac{\partial h_{l}}{\partial p_{0}}\right|_{T}=\left.\frac{\partial V_{g}}{\partial p_{0}}\right|_{T}=-\frac{N R T}{\left\{p_{0}+\beta\left[h_{l}+\gamma\left(h_{e}+\frac{1}{2} h_{s}\right)\right]\right\}^{2}}\left[1+\left.\beta \frac{\partial h_{l}}{\partial p_{0}}\right|_{T}\right] .
$$

This can also be derived by thinking of the supernate volume as the volume that would be present with no trapped gas in the tank plus the increase in volume from liquid displaced from the salt-cake/sludge layer by the trapped gas. Letting $h_{0}$ be the liquid height when there is no gas present, in equation form, we have

$$
A h_{l}=A h_{0}+V_{g} .
$$

Differentiating Eq. (A6) and using (A3) at constant temperature also leads to Eq. (A5). Substituting from Eq. (A3) into Eq. (A5) then gives the relationship

$$
\left.A \frac{\partial h_{l}}{\partial p_{0}}\right|_{T}=\left.\frac{\partial V_{g}}{\partial p_{0}}\right|_{T}=-\frac{\alpha_{s l} A h_{s}}{\left\{p_{0}+\beta\left[h_{l}+\gamma\left(h_{e}+\frac{1}{2} h_{s}\right)\right]\right\}}\left[1+\left.\beta \frac{\partial h_{l}}{\partial p_{0}}\right|_{T}\right] .
$$

We assume that the salt-cake/sludge layer height is constant. That is, as gas bubbles build up or collapse in the trapped gas layer, they displace liquid from this layer into the supernate. Therefore, the change in supernate level is also equal to the change in waste level in the tank. In fact, we can eliminate $h_{l}$ from the equations in favor of $h$ using the relationship

$$
h=h_{l}+h_{e}+h_{s} .
$$

Applying Eq. (A8) and assuming that $h_{e}$ and $h_{s}$ are constant, Eq. (A7) can be written as

$$
\left.\frac{\partial h}{\partial p_{0}}\right|_{T}=-\frac{\alpha_{s l} h_{s}}{\left\{p_{0}+\beta\left[h+(\gamma-1) h_{e}-\left(1-\frac{\gamma}{2}\right) h_{s}\right]\right\}}\left[1+\left.\beta \frac{\partial h}{\partial p_{0}}\right|_{T}\right] .
$$

Solving Eq. (A9) for the gas void fraction gives

$$
\alpha_{s l}=\frac{1}{h_{s}}\left(-\left.\frac{\partial h}{\partial p_{0}}\right|_{T}\right)\left[\frac{p_{0}+\beta\left\{h+(\gamma-1) h_{e}-\left(1-\frac{\gamma}{2}\right) h_{s}\right\}}{1+\left.\beta \frac{\partial h}{\partial p_{0}}\right|_{T}}\right] .
$$


If the terms multiplied by $\beta$ are small, Eq. (A10) reduces to

$$
\alpha_{s l}=\frac{p_{0}}{h_{s}}\left(-\frac{\partial h}{\partial p_{0}}\right)
$$

This equation differs from the original PNNL formulation Eq. (1) in that $\alpha_{s l}$ locates the gas void fraction in the salt-cake/sludge layer only. In general, the terms involving $\beta$ are not small and the more exact analysis presented above should be used in place of the PNNL simplification.

If we now define a reduced pressure as

$$
\hat{p}=\frac{p_{0}}{\beta}=\frac{p_{0}}{\rho g}
$$

and let $\delta=\gamma-1$, with $\frac{\partial \mathrm{h}}{\partial \mathrm{p}_{\mathrm{o}}}=\frac{\partial \mathrm{h}}{\partial \hat{\mathrm{p}}}(\rho \mathrm{g})$, then Eq. (A10) can be written in the simplified form given in Eq. (A13).

$$
\alpha_{s l}=\frac{\hat{p}}{h_{s}}\left(-\left.\frac{\partial h}{\partial \hat{p}}\right|_{T}\right)\left[\frac{1+\frac{1}{\hat{p}}\left\{h+\delta h_{e}-(1-\delta) \frac{h_{s}}{2}\right\}}{1+\left.\frac{\partial h}{\partial \hat{p}}\right|_{T}}\right]
$$

This relationship can be used to evaluate the gas volume fraction in the salt or sludge layer from changes in barometric pressure at constant temperature.

A similar analysis can be performed assuming that the system is at constant pressure instead of constant temperature. Differentiating Eqs. (A6) and (A3) at constant pressure gives

$$
\left.A \frac{\partial h_{l}}{\partial T}\right|_{P}=\left.\frac{\partial V_{g}}{\partial T}\right|_{P}=N R \frac{\left\{p_{0}+\beta\left[h_{l}+\gamma\left(h_{e}+\frac{1}{2} h_{s}\right)\right]\right\}-T\left[\left.\beta \frac{\partial h_{l}}{\partial T}\right|_{P}\right]}{\left\{p_{0}+\beta\left[h_{l}+\gamma\left(h_{e}+\frac{1}{2} h_{s}\right)\right]\right\}^{2}} .
$$

In deriving Eq. (A14), we neglect the change in liquid density with temperature and assume that any change in volume is primarily caused by expansion or contraction of the trapped gas. Using Eq. (A3) to simplify Eq. (A14), recognizing that the change in 
supernate level is equal to the change in the measured waste level, and using Eq. (A8) gives

$$
\left.\frac{\partial h}{\partial T}\right|_{P}=\alpha_{s l} h_{s}\left\{\frac{1}{T}-\frac{\left[\left.\beta \frac{\partial h}{\partial T}\right|_{P}\right]}{\left\{p_{0}+\beta\left[h+(\gamma-1) h_{e}-\left(1-\frac{\gamma}{2}\right) h_{s}\right]\right\}}\right\} .
$$

Solving Eq. (15) for the gas void fraction in the salt-cake/sludge layer, introducing the reduced pressure, and using the $\delta$ parameter yields the relationship

$$
\alpha_{s l}=\frac{T}{h_{s}}\left(\left.\frac{\partial h}{\partial T}\right|_{P}\right)\left\{1-\frac{T\left[\left.\frac{\partial h}{\partial T}\right|_{P}\right]}{\left[\hat{p}+\left\{h+\delta h_{e}-(1-\delta) \frac{h_{s}}{2}\right\}\right]}\right\}^{-1} \text {. (A16) }
$$

This relationship can be used to evaluate the gas volume fraction in the tank from changes in temperature at constant barometric pressure.

We can treat cases where the pressure and temperature are both varying by using the total derivative

$$
d h=\left.\frac{\partial h}{\partial T}\right|_{P} \dot{d} T+\left.\frac{\partial h}{\partial p}\right|_{T} d p .
$$

Using reduced pressure and $\delta$, Eq. (A9) can be rewritten as

$$
\left.\frac{\partial h}{\partial \hat{p}}\right|_{T}=-\frac{\alpha_{s l} h_{s}}{\left\{\hat{p}+\left[h+\delta h_{e}-(1-\delta) \frac{h_{s}}{2}\right]\right\}}\left[1+\left.\frac{\partial h}{\partial \hat{p}}\right|_{T}\right] .
$$

Solving for the derivative gives

$$
\left.\frac{\partial h}{\partial \hat{p}}\right|_{T}=-\frac{\alpha_{s l} h_{s}}{\alpha h_{s}+\left\{\hat{p}+\left[h+\delta h_{e}-(1-\delta) \frac{h_{s}}{2}\right]\right\}} .
$$


Using reduced pressure and $\delta$, Eq. (A15) can be rewritten as:

$$
\left.\frac{\partial h}{\partial T}\right|_{P}=\alpha_{s l} h_{s}\left\{\frac{1}{T}-\frac{\left[\left.\frac{\partial h}{\partial T}\right|_{P}\right]}{\left\{\hat{p}+\left[h+\delta h_{e}-(1-\delta) \frac{h_{s}}{2}\right]\right\}}\right\}
$$

Solving for the derivative, we obtain

$$
\left.\frac{\partial h}{\partial T}\right|_{P}=\frac{\frac{\alpha_{s l} h_{s}}{T}\left\{\hat{p}+\left[h+\delta h_{e}-(1-\delta) \frac{h_{s}}{2}\right]\right\}}{\alpha h_{s}+\left\{\hat{p}+\left[h+\delta h_{e}-(1-\delta) \frac{h_{s}}{2}\right]\right\}} .
$$

Now, the term $\hat{p}+\left[h+\delta h_{e}-(1-\delta) \frac{h_{s}}{2}\right]$ is the equivalent "head" of liquid at the average location of the trapped gas. To simplify our notation, we define this liquid head term to be $H$. Then the derivatives above become

$$
\left.\frac{\partial h}{\partial \hat{p}}\right|_{T}=-\frac{\alpha_{s l} h_{s}}{\alpha_{s l} h_{s}+H} \text { and }\left.\frac{\partial h}{\partial T}\right|_{P}=\frac{1}{T} \frac{\alpha_{s l} h_{s} H}{\alpha_{s l} h_{s}+H}
$$

The total derivative can be written as

$$
d h=\frac{\alpha_{s l} h_{s}}{\alpha_{s l} h_{s}+H}\left[\frac{H}{T} d T-d \hat{p}\right]=\frac{\alpha_{s l} h_{s}}{\alpha_{s l} h_{s}+H}[H d(\ln T)-d \hat{p}]
$$

where $H=\hat{p}+h+\delta h_{e}-(1-\delta) h_{s} / 2$ and $\hat{p}=p_{0} / \rho g$. All of the variables $p_{0}, T$ and $h$ and the derived quantities $\hat{p}$ and $H$ are functions of time. Solving Eq. (A23) for the gas void fraction gives

$$
\alpha_{s l}=\frac{H}{h_{s}} \frac{d h}{[H d(\ln T)-d \hat{p}]-d h} .
$$

If we argue that Eq. (A24) can be applied over some period of time using a mean value for the equivalent liquid head parameter $(\bar{H})$, then we can collect terms in the denominator on the right-hand-side of the equation into

$$
H d(\ln T)-d \hat{p} \cong d(\bar{H} \ln T)-d \hat{p}=d(\bar{H} \ln T-\hat{p})=d \psi
$$


where we define the variable $\psi=\bar{H} \ln T-\hat{p}$.

Then, using Eq. (A24), the value of $\alpha$ can be estimated from the relationship

$$
\alpha_{s l}=\frac{\bar{H}}{h_{s}} \frac{d h / d \psi}{1-d h / d \psi} .
$$

The analysis method is similar to that presented before by Weber and Smith:

1. Identify a period in the record of tank waste level where the level appears to change at a relatively constant rate and "detrend" this time period by removing the constant rate of change from the data. The detrending is intended to remove factors not accounted for in the analysis such as evaporation, condensation, leakage or waste transfers. If the linear change is thought to be caused by pressure or temperature variations this step should not be used.

2. Using the detrended data and the average value of $H$ over the time period, correlate waste height $h$ against the parameter $\psi$ and find the best fitting slope to calculate $d h / d \psi$.

3. With the slope calculated, Eq. (A26) can be used to estimate the value of $\alpha_{s l^{\circ}}$

This analysis accounts for the effect of both temperature and pressure on trapped gas. The analysis assumes that the temperature change is not large so that changes in liquid density can be neglected (or that there is enough gas present such that the change in gas volume is much greater than the change in liquid volume). The analysis also assumes that no other factors such as evaporation, condensation, waste addition, leakage, etc, are contributing to a change in the liquid level. 


\section{Appendix B: Uncertainty Analysis}

The total variance for the void fraction measurement depends on computing the variance of $\alpha$ due to the following measured variables: $\rho_{s^{\prime}} h_{e^{\prime}} h_{s^{\prime}} \rho, T_{t^{\prime}} P_{t^{\prime}}$ and $h_{t^{\prime}}$. The slope $\eta=d h / d \psi$ is also estimated from these seven measured quantities. Each of the variables in Eq. (A26) is a function of one or more terms. Eqs. (A27) through (A30) could be substituted back into Eq. (A26). A first-order Taylor Series approximation is then used to approximate the variance of $\alpha$ by calculating the partial derivatives of $\alpha$ with respect to each of the measured variables. Instead of substituting Eqs. (A2) through (A30) back into Eq. (A26), the chain rule can be used to compute the appropriate partial derivatives for the Taylor Series approximation.

The chain rule will give the following derivations of the partial derivatives:

$$
\begin{aligned}
& \frac{\partial \alpha}{\partial \rho_{s}}=\frac{\partial \alpha}{\partial \overline{\mathrm{H}}} \frac{\partial \overline{\mathrm{H}}}{\partial \rho_{\mathrm{s}}}+\frac{\partial \alpha}{\partial \hat{\eta}} \sum_{\mathrm{t}=1}^{\mathrm{n}}\left[\frac{\partial \bar{\eta}}{\partial \Psi_{\mathrm{t}}} \frac{\partial \Psi_{\mathrm{t}}}{\partial \overline{\mathrm{H}}} \frac{\partial \overline{\mathrm{H}}}{\partial \rho_{\mathrm{s}}}+\frac{\partial \hat{\eta}}{\partial \mathrm{h}_{\mathrm{t}}} \frac{\partial \mathrm{h}_{\mathrm{t}}}{\partial \rho_{\mathrm{s}}}\right] \frac{\partial \mathrm{h}_{\mathrm{t}}}{\partial \rho_{\mathrm{s}}}=0 \text { for all t } \\
& \frac{\partial \alpha}{\partial \mathrm{h}_{\mathrm{e}}}=\frac{\partial \alpha}{\partial \overline{\mathrm{H}}} \frac{\partial \overline{\mathrm{H}}}{\partial \mathrm{h}_{\mathrm{e}}}+\frac{\partial \alpha}{\partial \hat{\eta}} \sum_{\mathrm{t}=1}^{\mathrm{n}}\left[\frac{\partial \bar{\eta}}{\partial \Psi_{\mathrm{t}}} \frac{\partial \Psi_{\mathrm{t}}}{\partial \overline{\mathrm{H}}} \frac{\partial \overline{\mathrm{H}}}{\partial \mathrm{h}_{\mathrm{e}}}+\frac{\partial \hat{\eta}}{\partial \mathrm{h}_{\mathrm{t}}} \frac{\partial \mathrm{h}_{\mathrm{t}}}{\partial \mathrm{h}_{e}}\right], \frac{\partial \mathrm{h}_{\mathrm{e}}}{\partial \mathrm{h}_{\mathrm{e}}}=0 \text { for all } \mathrm{t} \\
& \frac{\partial \alpha}{\partial \mathrm{h}_{s}}=\frac{\partial \alpha}{\partial \mathrm{h}_{s}}+\frac{\partial \alpha}{\partial \overline{\mathrm{H}}} \frac{\partial \overline{\mathrm{H}}}{\partial \mathrm{h}_{\mathrm{s}}}+\frac{\partial \alpha}{\partial \hat{\eta}} \sum_{\mathrm{t}=1}^{\mathrm{n}}\left[\frac{\partial \bar{\eta}}{\partial \Psi_{\mathrm{t}}} \frac{\partial \Psi_{\mathrm{t}}}{\partial \overline{\mathrm{H}}} \frac{\partial \overline{\mathrm{H}}}{\partial \mathrm{h}_{s}}+\frac{\partial \hat{\eta}}{\partial \mathrm{h}_{\mathrm{t}}} \frac{\partial \mathrm{h}_{\mathrm{t}}}{\partial \mathrm{h}_{\mathrm{s}}}\right], \frac{\partial \mathrm{h}_{\mathrm{t}}}{\partial \mathrm{h}_{s}}=0 \text { for all } \mathrm{t}
\end{aligned}
$$

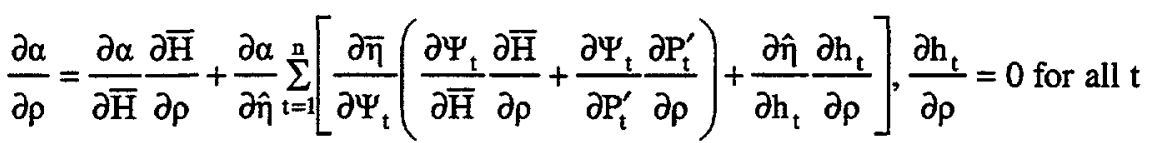

$$
\begin{aligned}
& \frac{\partial \alpha}{\partial T_{t}}=\frac{\partial \alpha}{\partial \hat{\eta}}\left(\frac{\partial \hat{\eta}}{\partial \Psi_{t}} \frac{\partial \Psi_{t}}{\partial T_{t}}+\frac{\partial \hat{\eta}}{\partial h_{t}} \frac{\partial h_{t}}{\partial T_{t}}\right), \frac{\partial h_{t}}{\partial T_{t}}=0 \text { for all } t \\
& \frac{\partial \alpha}{\partial \mathrm{P}_{\mathrm{t}}}=\frac{\partial \alpha}{\partial \overline{\mathrm{H}}} \frac{\partial \overline{\mathrm{H}}}{\partial \mathrm{P}_{\mathrm{t}}}+\frac{\partial \alpha}{\partial \hat{\eta}}\left[\sum_{t=1}^{\mathrm{n}} \frac{\partial \hat{\eta}}{\partial \Psi_{\mathrm{t}}}\left(\frac{\partial \Psi_{t}}{\partial \overline{\mathrm{H}}} \frac{\partial \overline{\mathrm{H}}}{\partial \mathrm{P}_{\mathrm{t}}}\right)+\frac{\partial \hat{\eta}}{\partial \Psi_{\mathrm{t}}} \frac{\partial \Psi_{t}}{\partial \mathrm{P}_{\mathrm{t}}^{\prime}} \frac{\partial \mathrm{P}_{\mathrm{t}}^{\prime}}{\partial \mathrm{P}_{\mathrm{t}}}+\frac{\partial \hat{\eta}}{\partial \mathrm{h}_{\mathrm{t}}} \frac{\partial \mathrm{h}_{\mathrm{t}}}{\partial \mathrm{P}_{\mathrm{t}}}\right], \frac{\partial \mathrm{h}_{\mathrm{t}}}{\partial \mathrm{P}_{\mathrm{t}}}=0 \text { for all } \mathrm{t} \\
& \frac{\partial \alpha}{\partial \mathrm{h}_{\mathrm{t}}}=\frac{\partial \alpha}{\partial \overline{\mathrm{H}}} \frac{\partial \overline{\mathrm{H}}}{\partial \mathrm{h}_{\mathrm{t}}}+\frac{\partial \alpha}{\partial \hat{\eta}}\left[\sum_{\mathrm{t}=1}^{\mathrm{n}} \frac{\partial \hat{\eta}}{\partial \Psi_{\mathrm{t}}} \frac{\partial \Psi_{\mathrm{t}}}{\partial \overline{\mathrm{H}}} \frac{\partial \overline{\mathrm{H}}}{\partial \mathrm{h}_{\mathrm{t}}}+\frac{\partial \hat{\eta}}{\partial \mathrm{h}_{\mathrm{t}}}\right] \text {. }
\end{aligned}
$$

Summarizing equations from the previous section we have:

$$
\alpha=\frac{\bar{H} \hat{\eta}}{h_{s}(1-\hat{\eta})},
$$




$$
\begin{aligned}
& \overline{\mathrm{H}}=\frac{\overline{\mathrm{P}}}{\rho \mathrm{g}}+\overline{\mathrm{h}}+\left[\left(\frac{\rho_{\mathrm{s}}}{\rho}-1\right) \mathrm{h}_{\mathrm{e}}-\left(2-\frac{\rho_{\mathrm{s}}}{\rho}\right) \frac{\mathrm{h}_{\mathrm{s}}}{2}\right] \\
& \hat{\eta}=\frac{\sum_{t=1}^{n}\left(\mathrm{~h}_{\mathrm{t}}-\overline{\mathrm{h}}\right)\left(\Psi_{t}-\bar{\Psi}\right)}{\sum_{t=1}^{n}\left(\Psi_{t}-\bar{\Psi}\right)^{2}}, \text { and } \\
& \Psi_{\mathrm{t}}=\overline{\mathrm{H}} \operatorname{Ln}\left(\mathrm{T}_{\mathrm{t}}\right)-\frac{P_{\mathrm{t}}}{\rho \mathrm{g}}
\end{aligned}
$$

Define the following combinations of the above variables.

$$
\begin{aligned}
& A=\frac{\partial \alpha}{\partial \overline{\mathrm{H}}}=\frac{\hat{\eta}}{h_{s}(1-\hat{\eta})} . \\
& B=\frac{\partial \alpha}{\partial \hat{\eta}}=\frac{\bar{H}}{h_{s}(1-\hat{\eta})^{2}} . \\
& C=\sum_{t=1}^{n} \frac{\partial \hat{\eta}}{\partial \Psi_{t}} \frac{\partial \psi_{t}}{\partial \bar{H}}=\frac{\sum_{t=1}^{n} \operatorname{Ln}\left(T_{t}\right)\left[\left(h_{t}-\bar{h}\right)-2 \hat{\eta}\left(\Psi_{t}-\bar{\Psi}\right)\right]}{\sum_{t=1}^{n}\left(\Psi_{t}-\bar{\Psi}\right)^{2}} \\
& D=\sum_{t=1}^{n} \frac{\partial \hat{\eta}}{\partial \Psi_{t}} \frac{\partial \Psi_{t}}{\partial P_{t}^{\prime}} \frac{\partial P_{t}^{\prime}}{\partial \rho}=\frac{\sum_{t=1}^{n} P_{t}\left[\left(h_{t}-\bar{h}\right)-2 \hat{\eta}\left(\Psi_{t}-\bar{\Psi}\right)\right]}{\sum_{t=1}^{n}\left(\Psi_{t}-\bar{\Psi}\right)^{2}} \\
& E=\sum_{t=1}^{n}\left\{\left(\frac{\partial \hat{\eta}}{\partial \Psi_{t}}\right)\left(\frac{\partial \Psi_{t}}{\partial T_{t}}\right)\right\}^{2}=\frac{\sum_{t=1}^{n}\left(\frac{1}{T_{t}}\right)^{2}\left[\left(h_{t}-\bar{h}\right)-2 \hat{\eta}\left(\Psi_{t}-\bar{\Psi}\right)\right]^{2}}{\left(\sum_{t=1}^{n}\left(\Psi_{t}-\bar{\Psi}\right)^{2}\right)^{2}} . \\
& F=\sum_{t=1}^{n}\left(h_{t}-\bar{h}\right)^{2} . \\
& G=\sum_{t=1}^{n}\left(\Psi_{t}-\bar{\Psi}\right)^{2} .
\end{aligned}
$$


There are 7 terms to the uncertainty in the void fraction. Each term corresponds to the variance component due to uncertainty in the seven measured variables plus the estimation of the slope, $\hat{\eta}$.

Term 1: Variance component due to measuring $\rho_{\mathrm{s}}$

$$
\left(\frac{\partial \alpha}{\partial \rho_{s}}\right)^{2} \operatorname{Var}\left(\rho_{s}\right)=\left(\frac{2 h_{e}+h_{s}}{2 p}\right)^{2}(A+B C)^{2} \operatorname{Var}\left(\rho_{s}\right) .
$$

Term 2: Variance component due to measuring $h_{e}$

$$
\left(\frac{\partial \alpha}{\partial h_{e}}\right)^{2} \operatorname{Var}\left(h_{e}\right)=\left(\frac{\rho_{s}-\rho}{\rho}\right)^{2}(A+B C)^{2} \operatorname{Var}\left(h_{e}\right) .
$$

Term 3: Variance component due to measuring $h_{s}$

$$
\left(\frac{\partial \alpha}{\partial h_{s}}\right)^{2} \operatorname{Var}\left(h_{s}\right)=\left(-\left(\frac{\bar{H}}{h_{s}}\right) A+\left(\frac{\rho_{s}-2 \rho}{2 \rho}\right)(A+B C)\right)^{2} \operatorname{Var}\left(h_{s}\right) .
$$

Term 4: Variance component due to measuring $\rho$

$$
\begin{aligned}
\left(\frac{\partial \alpha}{\partial \rho}\right)^{2} \operatorname{Var}(\rho) & =\left\{\left(\frac{(-1)\left(2 \mathrm{~g} \rho_{s} h_{\mathrm{e}}+\mathrm{g} \rho_{\mathrm{s}} \mathrm{h}_{s}+2 \overline{\mathrm{p}}\right)}{2 \mathrm{~g} \rho^{2}}\right)(\mathrm{A}+\mathrm{BC})+\left(\frac{\mathrm{B}}{\mathrm{g} \rho^{2}}\right)\left\{\frac{\sum_{t=1}^{\mathrm{n}}\left(\mathrm{P}_{\mathrm{t}}\right)\left[\left(\mathrm{h}_{\mathrm{t}}-\overline{\mathrm{h}}\right)-2 \hat{\eta}\left(\Psi_{\mathrm{t}}-\bar{\Psi}\right)\right]}{\sum_{\mathrm{t}=1}^{\mathrm{n}}\left(\Psi_{\mathrm{t}}-\bar{\Psi}\right)^{2}}\right)\right\}^{2} \operatorname{Var}(\rho) \\
& =\left\{\left(\frac{(-1)\left(2 \mathrm{~g} \rho_{\mathrm{s}} \mathrm{h}_{\mathrm{e}}+\mathrm{g} \rho_{\mathrm{s}} \mathrm{h}_{\mathrm{s}}+2 \overline{\mathrm{p}}\right)}{2 \mathrm{~g} \rho^{2}}\right)(\mathrm{A}+\mathrm{BC})+\left(\frac{\mathrm{BD}}{\mathrm{g} \rho^{2}}\right)\right\}^{2} \operatorname{Var}(\rho)
\end{aligned}
$$

Term 5: Variance due to Temperature $T_{t}$

$$
\sum_{t=1}^{n}\left(\frac{\partial \alpha}{\partial T_{t}}\right)^{2} \operatorname{Var}\left(T_{t}\right)=\left(\frac{\bar{H}^{2}}{h_{s}(1-\hat{\eta})^{2}}\right)^{2}\left(\frac{\sum_{t=1}^{n}\left(\frac{1}{T_{t}}\right)^{2}\left[\left(h_{t}-\bar{h}\right)-2 \hat{\eta}\left(\Psi_{t}-\bar{\Psi}\right)\right]}{\left(\sum_{t=1}^{n}\left(\Psi_{t}-\bar{\Psi}\right)^{2}\right)^{2}}\right) \operatorname{Var}\left(T_{t}\right) .
$$




$$
\sum_{t=1}^{n}\left(\frac{\partial \alpha}{\partial T_{t}}\right)^{2} \operatorname{Var}\left(T_{t}\right)=(\bar{H} B)^{2}(E) \operatorname{Var}(T)
$$

Term 6: Variance due to $P_{\text {, }}$

$$
\sum_{t=1}^{n}\left(\frac{\partial \alpha}{\partial P_{t}}\right)^{2} \operatorname{Var}\left(P_{t}\right)=\left(\frac{1}{\rho g}\right)^{2}\left[\left((A+B C)^{2}+\left(\frac{n B^{2} \sum_{t=1}^{n}\left(h_{t}-\bar{h}\right)^{2}}{\left(\sum_{t=1}^{n}\left(\Psi_{t}-\bar{\Psi}\right)^{2}\right)^{2}}\right)\right] \frac{\operatorname{Var}\left(P_{t}\right)}{n}\right.
$$

Term 7: Variance component due to measuring $h_{t}$

$$
\sum_{t=1}^{n}\left(\frac{\partial \alpha}{\partial h_{t}}\right)^{2} \operatorname{Var}\left(h_{t}\right)=\left[(A+B C)^{2}+\frac{n B^{2}}{\sum_{t=1}^{n}\left(\Psi_{t}-\bar{\Psi}\right)^{2}}\right] \frac{\operatorname{Var}\left(h_{t}\right)}{n}
$$

$$
\operatorname{Var}(\alpha)=\operatorname{Term} 1+\operatorname{Term} 2+\operatorname{Term} 3+\operatorname{Term} 4+\operatorname{Term} 5+\operatorname{Term} 6+\operatorname{Term} 7
$$

The standard deviation of $\alpha$ is the square root of the variance from Eq. (B46).

$$
\operatorname{SD}(\alpha)=\sqrt{\operatorname{Var}(\alpha)}
$$

The $95 \%$ confidence limits are:

$$
\alpha \pm 2 \operatorname{SD}(\alpha)
$$




\section{Appendix C: Salt Solubility Relations and Mass Exchange Equations}

Duignan has fit the solubility data for $\mathrm{NaNO}_{3}$ and $\mathrm{NaOH}$ to the empirical form

$$
w t \%=a_{0}+a_{1} T+a_{2} T^{2} .
$$

The equation coefficients are interpolated from the following data

Table $\mathrm{C} 1$. Table of coefficients for determining the weight percent of $\mathrm{NaNO}_{3}$ and $\mathrm{NaOH}$ by empirical formula.

\begin{tabular}{|c|c|c|c|}
\hline Solution & $a_{0}$ & $a_{1}$ & $a_{2}$ \\
\hline $\mathbf{1}$ & 61.629 & -0.230 & 0.005 \\
\hline $\mathbf{2}$ & 48.978 & 0.295 & 0 \\
\hline $\mathbf{3}$ & 34.821 & 0.328 & 0 \\
\hline $\mathbf{4}$ & 48.532 & 0.212 & 0 \\
\hline $\mathbf{5}$ & 45.457 & 0.130 & 0 \\
\hline
\end{tabular}

Where the solution used is a function of the salt molarity according to the following table.

Table C2. $\mathrm{NaOH}$ and $\mathrm{NaNO}_{3}$ molarities for two different solutions.

\begin{tabular}{|c|c|c|c|}
\hline $\begin{array}{c}\text { NaOH } \\
\text { Molarity }\end{array}$ & Solution & $\begin{array}{c}\text { NaNO }_{3} \\
\text { Molarity }\end{array}$ & Solution \\
\hline 0.59 & 2 & 2.18 & 4 \\
\hline 1.00 & 5 & 2.69 & 1 \\
\hline 2.52 & 3 & 5.03 & 3 \\
\hline 4.43 & 1 & 6.00 & 5 \\
\hline 7.60 & 4 & 6.64 & 2 \\
\hline
\end{tabular}

To estimate the solubility of either salt, values of the coefficients are linearly interpolated based on the above tables. Duignan then simply averages the two coefficients to obtain a solubility equation. For example, if the solution is $1.76 \mathrm{M} \mathrm{NaOH}$ and $1.0 \mathrm{M} \mathrm{NaNO}_{3}$ $\left(\mathrm{NaNO}_{2}\right.$ is assumed to behave like $\mathrm{NaNO}_{3}$ ), the second table indicates that we interpolate 
between the coefficients for Solution 5 and Solution 3 for $\mathrm{NaOH}$ solubility and that we use the coefficients for Solution 4 for $\mathrm{NaNO}_{3}$. Therefore, for this example, the solubility coefficients would be given by

$$
\begin{aligned}
& a_{0}=\frac{1}{2}\left\{34.821\left[\frac{1.76-1.00}{2.52-1.00}\right]+45.457\left[\frac{2.52-1.76}{2.52-1.00}\right]+48.532\right\}=44.336 \\
& a_{1}=\frac{1}{2}\left\{0.328\left[\frac{1.76-1.00}{2.52-1.00}\right]+0.130\left[\frac{2.52-1.76}{2.52-1.00}\right]+0.212\right\}=0.220 \\
& a_{2}=0.0
\end{aligned}
$$

Therefore, the solubility of this salt composition would be calculated from the equation

$$
w t \%=44.336+0.220 T .
$$

Now define the following terms:

$$
\begin{aligned}
& M_{1} \text {............ total salt solution mass at temperature } T_{1} \text {, } \\
& \mathrm{M}_{2} \ldots \ldots . . . . . . \text { total salt solution mass at temperature } T_{2} \text {, } \\
& S_{1} \text {............ mass of salt in solution at temperature } T_{1} \text {, } \\
& \mathrm{S}_{2} \text {............ mass of salt in solution at temperature } \mathrm{T}_{2} \text {, and } \\
& \text { W ............. mass of water in the salt solution. }
\end{aligned}
$$

By definition the solution masses at the two temperatures are

$$
M_{1}=W+S_{1} \text { and } M_{2}=W+S_{2} \text {. }
$$

The weight fractions of salt in solution at the two temperatures are

$$
\omega t_{1}=S_{1} / M_{1} \text { and } \omega t_{2}=S_{2} / M_{2} \text {. }
$$

The change in mass of the salt solution between temperatures $T_{1}$ and $T_{2}$ caused be either dissolving salt into the solution or precipitating salt out of solution can be calculated as

$$
\Delta \mathrm{m}=\mathrm{M}_{2}-\mathrm{M}_{1}=\mathrm{S}_{2}-\mathrm{S}_{1}=\omega t_{2} \mathrm{M}_{2}-\omega t_{1} \mathrm{M}_{1}
$$

The above relations can be combined and rearranged to obtain:

$$
\begin{aligned}
& M_{2}=W+S_{2}=M_{1}-S_{1}+S_{2}=M_{1}-\omega t_{1} M_{1}+\omega t_{2} M_{2} \\
& M_{2}=\left(1-\omega t_{1}\right) M_{1} /\left(1-\omega t_{2}\right) .
\end{aligned}
$$


Using this expression to eliminate $M_{2}$ from the equation for the change in mass and rearranging the result leads to the relationship

$$
\Delta \mathrm{m}=\mathrm{M}_{1}\left(\omega t_{2}-\omega t_{1}\right) /\left(1-\omega t_{2}\right) .
$$

This equation can be used to calculate the change in mass in the solution as the temperature changes from $T_{1}$ to $T_{2}$. We apply this equation to both the salt solution above the salt-cake (supernate) and to the salt solution within the saltcake. The assumption is that both solutions will dissolve or precipitate salt to remain at saturation in response to temperature changes. The masses of the salt solutions at $T_{1}$ are calculated as:

$$
\left(\mathrm{M}_{1}\right)_{\text {supernate }}=\left(\mathrm{H}_{\mathrm{w}}-\mathrm{H}_{\mathrm{sc}}\right) \mathrm{C} \rho_{\text {liq }} \text { and }\left(\mathrm{M}_{1}\right)_{\mathrm{sc}}=\mathrm{H}_{\mathrm{sc}} \chi_{\mathrm{sc}} \mathrm{C} \rho_{\text {liq' }}
$$

where $C$ is the factor needed to convert tank height into volume and $\rho_{\mathrm{liq}}$ is the liquid density. Then the change in mass in the two liquid volumes can be calculated from the equations:

$$
\begin{gathered}
(\Delta \mathrm{m})_{\text {supernate }}=\left(\mathrm{H}_{\mathrm{w}}-\mathrm{H}_{\mathrm{sc}}\right) C \rho_{\mathrm{liq}}\left[\left(\omega t_{2}-\omega t_{1}\right) /\left(1-\omega t_{2}\right)\right]_{\text {supernate }} \\
(\Delta \mathrm{m})_{\mathrm{sc}}=\mathrm{H}_{\mathrm{sc}} \chi_{\mathrm{sc}} C \rho_{\mathrm{liq}}\left[\left(\omega t_{2}-\omega t_{1}\right) /\left(1-\omega t_{2}\right)\right]_{\mathrm{sc}}
\end{gathered}
$$

Introducing the following functions to simplify the notation,

$$
\phi_{1}=\left[\frac{\omega t_{2}-\omega t_{1}}{1-\omega t_{2}}\right]_{\text {supernate }} \text { and } \phi_{2}=\left[\frac{\omega t_{2}-\omega t_{1}}{1-\omega t_{2}}\right]_{s c^{\prime}}
$$

the expressions for the change in mass can also be written as

$$
(\Delta \mathrm{m})_{\text {supernate }}=\left(\mathrm{H}_{\mathrm{w}}-\mathrm{H}_{\mathrm{sc}}\right) \mathrm{C} \rho_{\mathrm{liq}} \phi_{1} \text { and }(\Delta \mathrm{m})_{\mathrm{sc}}=\mathrm{H}_{\mathrm{sc}} \chi_{\mathrm{sc}} \mathrm{C} \rho_{\mathrm{liq}} \phi_{2} \text {. }
$$

As salt changes phase from the liquid solution to the salt-cake, the solid and liquid volumes both change. The net change in waste level is the difference between these changes.

$$
\begin{aligned}
& \Delta \mathrm{H}=\Delta \mathrm{H}_{\text {supernate }}-\Delta \mathrm{H}_{\mathrm{sc}} \\
& \Delta \mathrm{H}=\left[(\Delta \mathrm{m})_{\text {supernate }}+(\Delta \mathrm{m})_{\mathrm{sc}}\right] /\left[C \rho_{\text {liq }}\right]-\left[(\Delta \mathrm{m})_{\text {supernate }}+(\Delta \mathrm{m})_{\mathrm{sc}}\right] /\left[C \rho_{\mathrm{sc}}\right] .
\end{aligned}
$$

Combining the above relationships gives the final equation for the change in waste level

$$
\Delta \mathrm{H}=\left[\left(\mathrm{H}_{\mathrm{w}}-\mathrm{H}_{\mathrm{sc}}\right) \phi_{1}+\mathrm{H}_{\mathrm{sc}} \chi_{\mathrm{sc}} \phi_{2}\right]\left[1-\rho_{\mathrm{liq}} / \rho_{\mathrm{sc}}\right]
$$


The liquid density, or equivalently the specific gravity, is specified for each waste tank. The salt-cake density (or specific gravity) is calculated from the mass fraction of each salt component by the equation

$$
\rho_{\mathrm{sc}}=\sum_{i} x_{i} \rho_{i},
$$

where the component specific gravities are $\mathrm{NaOH}=2.130, \mathrm{NaNO}_{2}=2.168$ and $\mathrm{NaNO}_{3}$. 


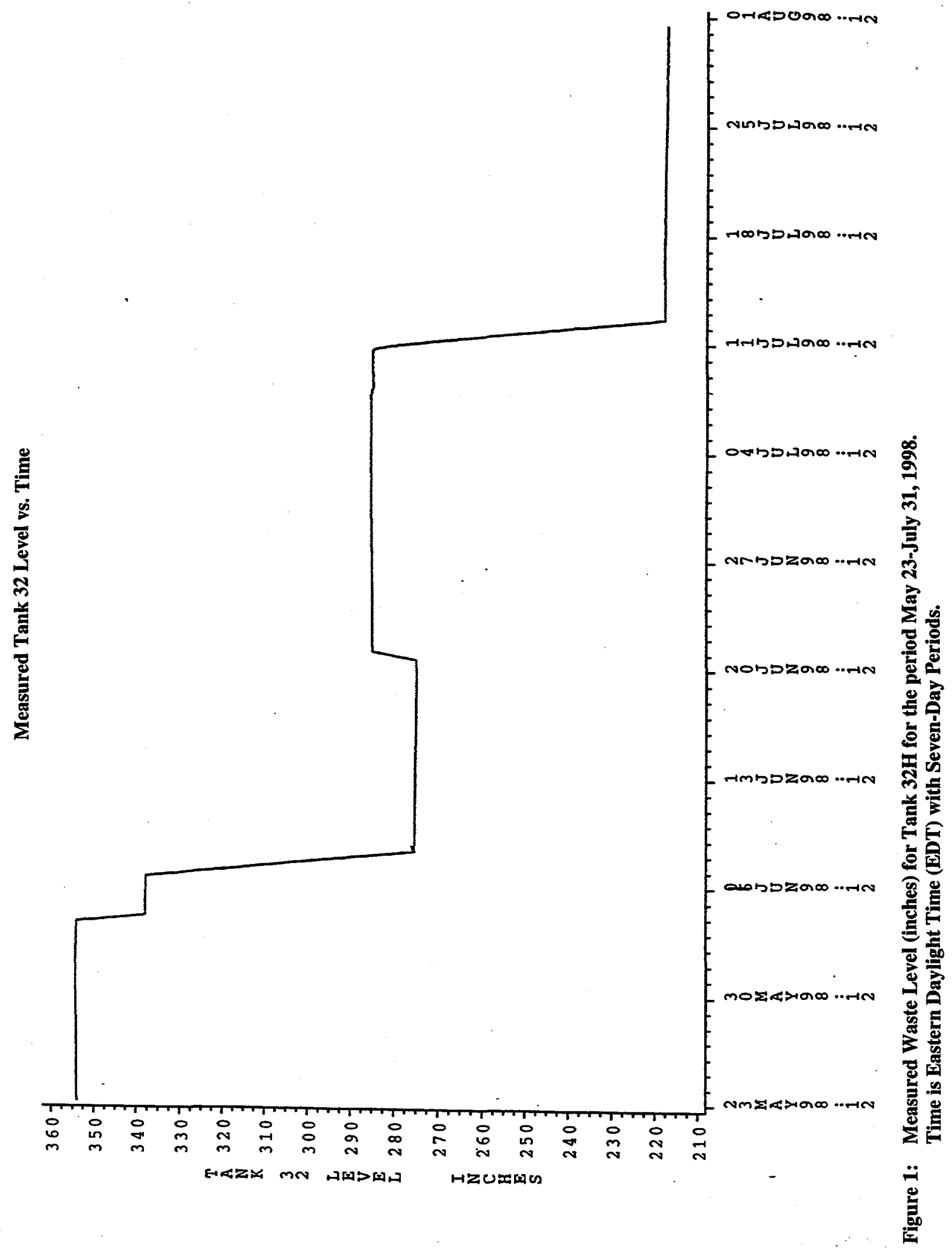




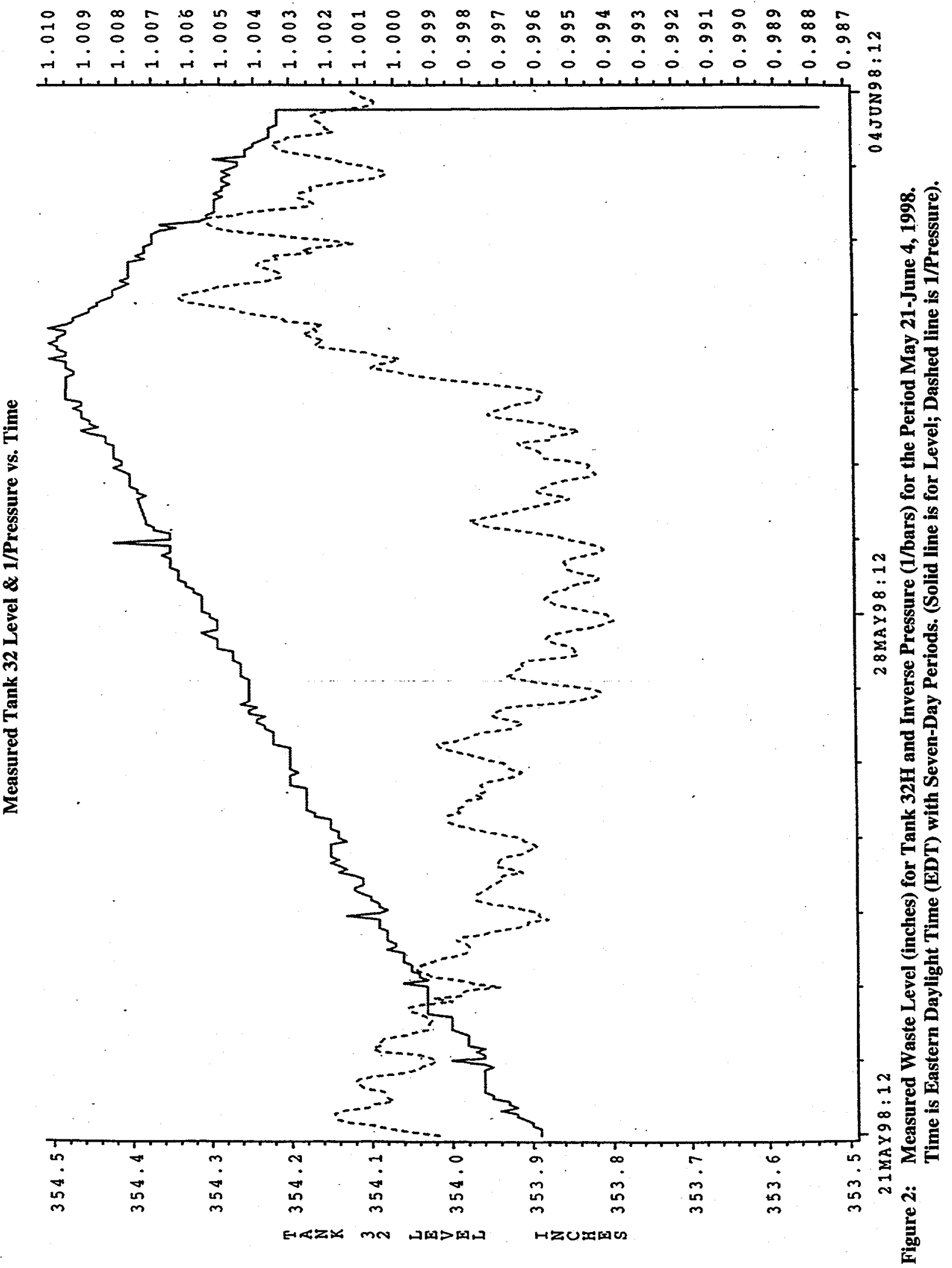

n 
Measured Tank 32 Level and 1/Pressure vs. Time (Pre-Transfer)

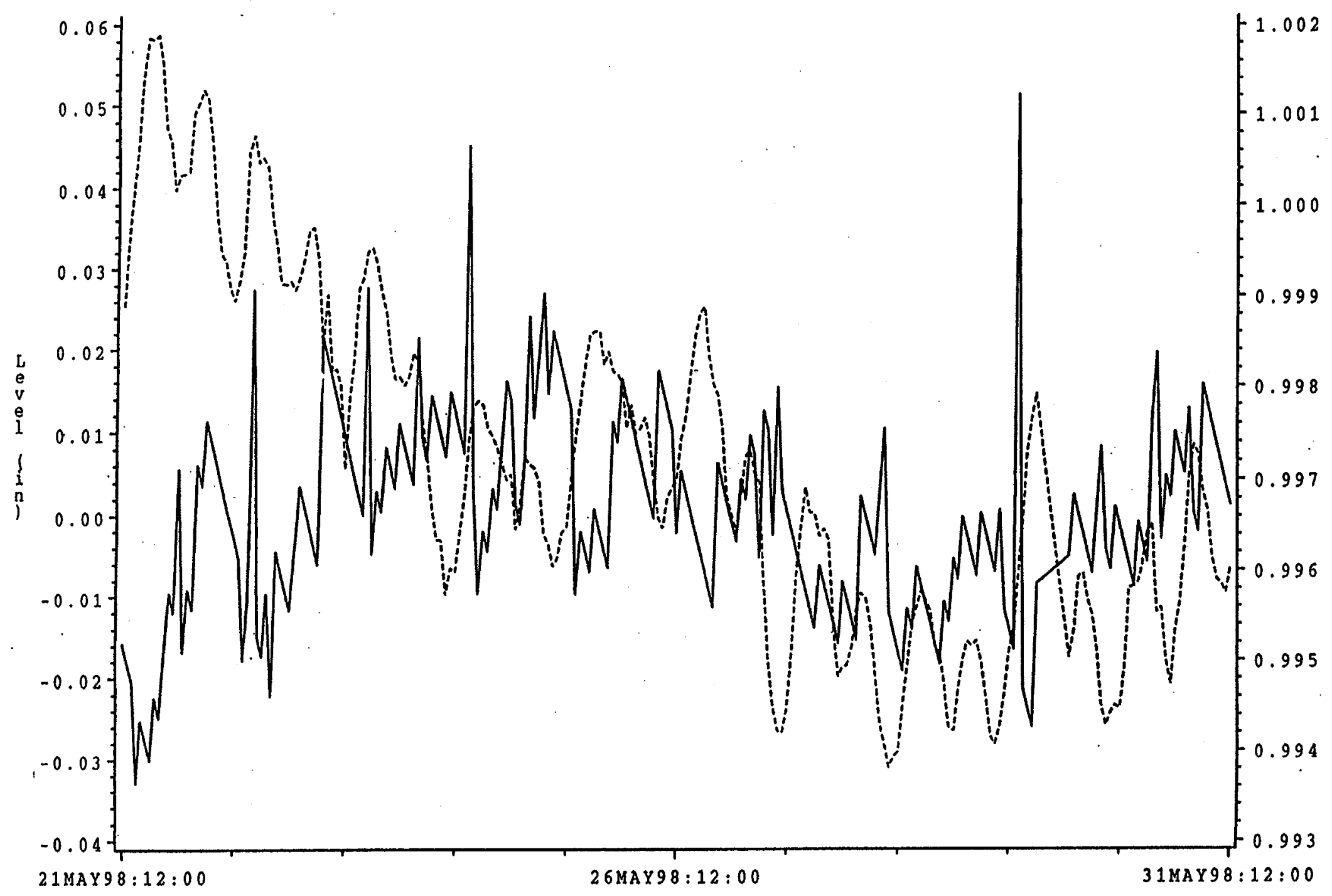

Figure 3: Measured Waste Residual Level for Tank 32H and Inverse Pressure (1/bars) for the Period May 21-31, 1998.

Time is Eastern Daylight Time (EDT) with Seven-Day Periods. (Solid Line is for Level. Dashed line is 1/Pressure). 
Spectrum of Pressure (Pre-transfer)

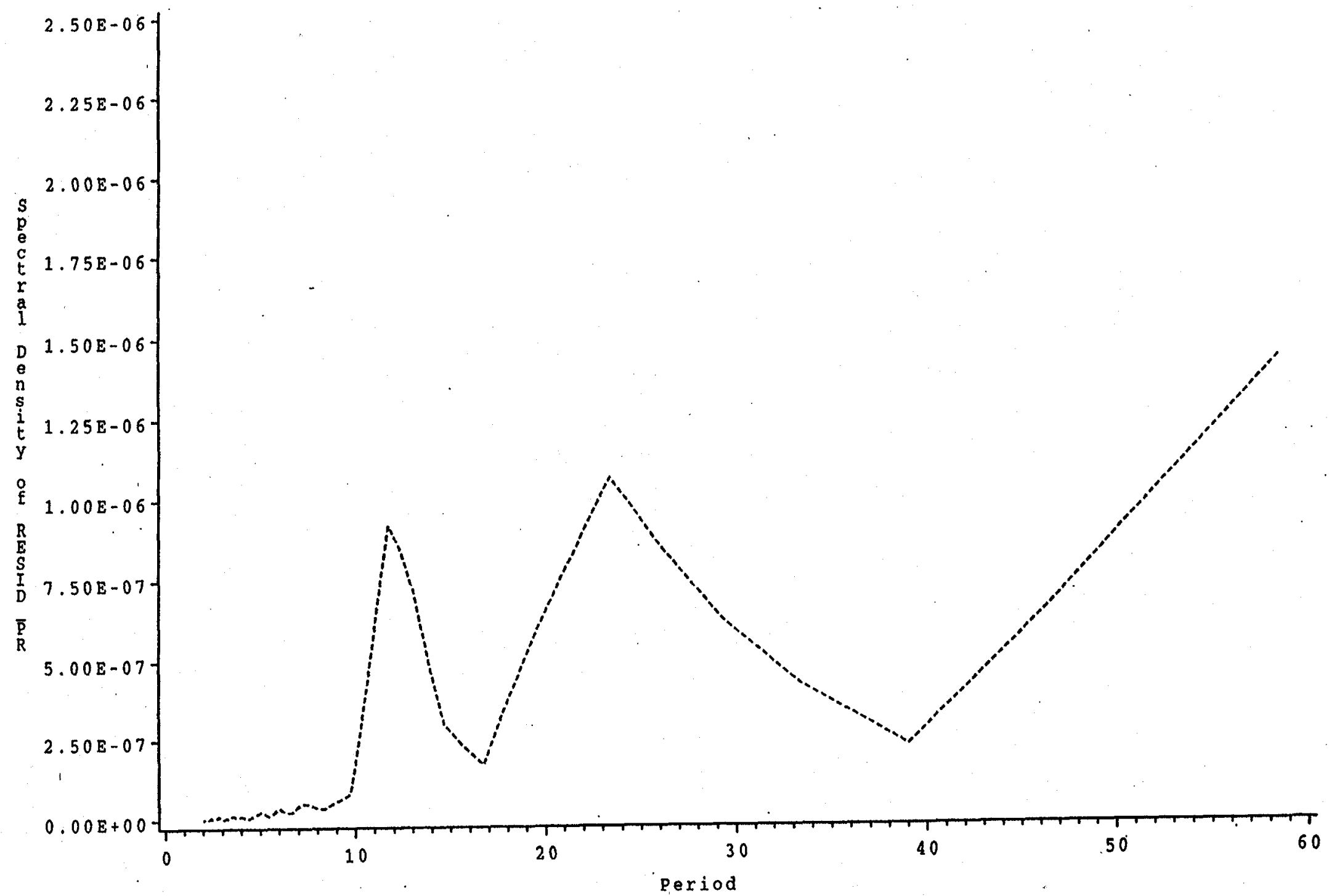

Figure 4: Spectral Density of Measured Atmospheric Pressure for the Period May 21-31, 1998. Period in Hours.

39 


\section{Spectrum of Residual Level (Pre-transfer)}

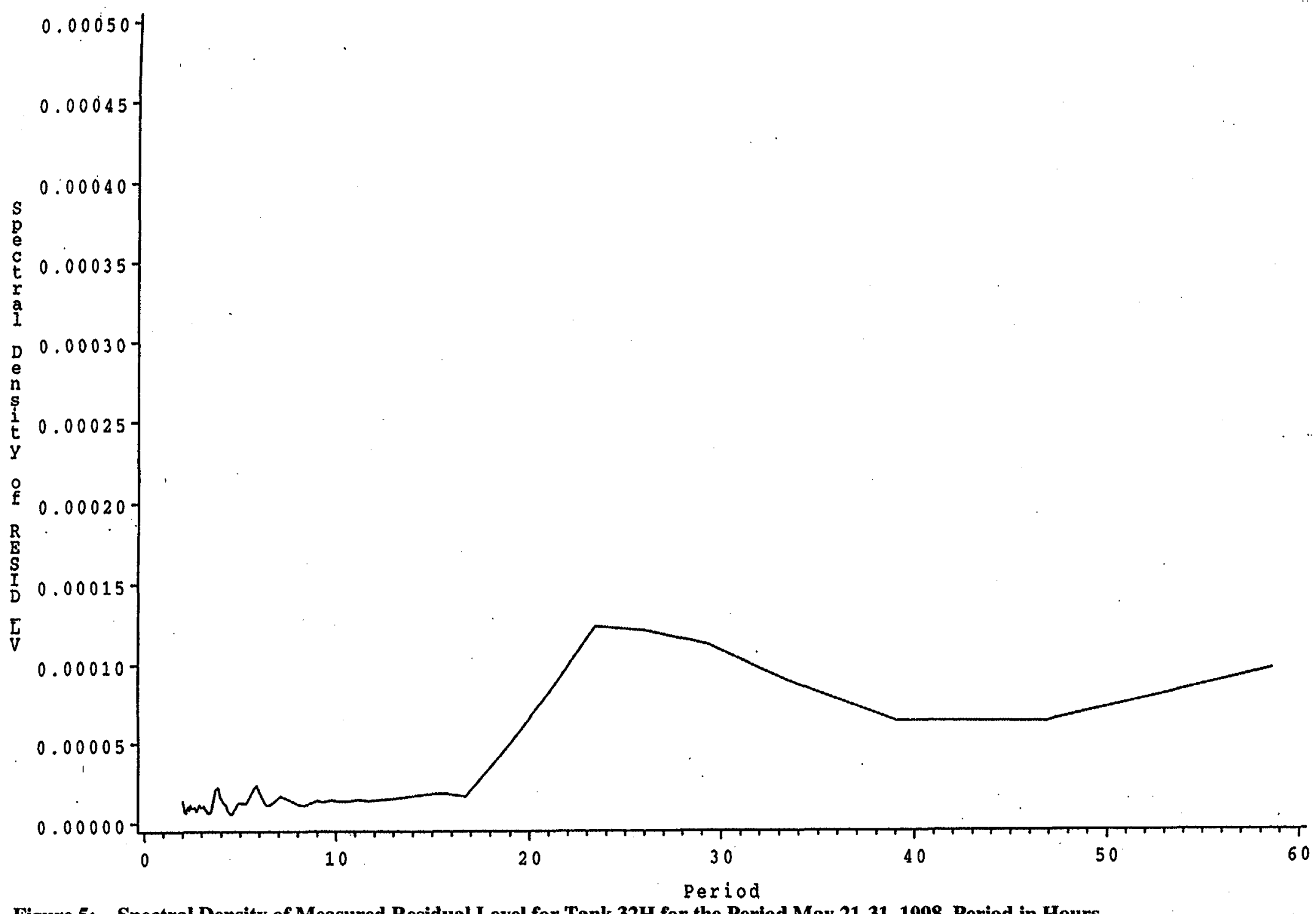

Figure 5: Spectral Density of Measured Residual Level for Tank 32H for the Period May 21-31, 1998. Period in Hours. 


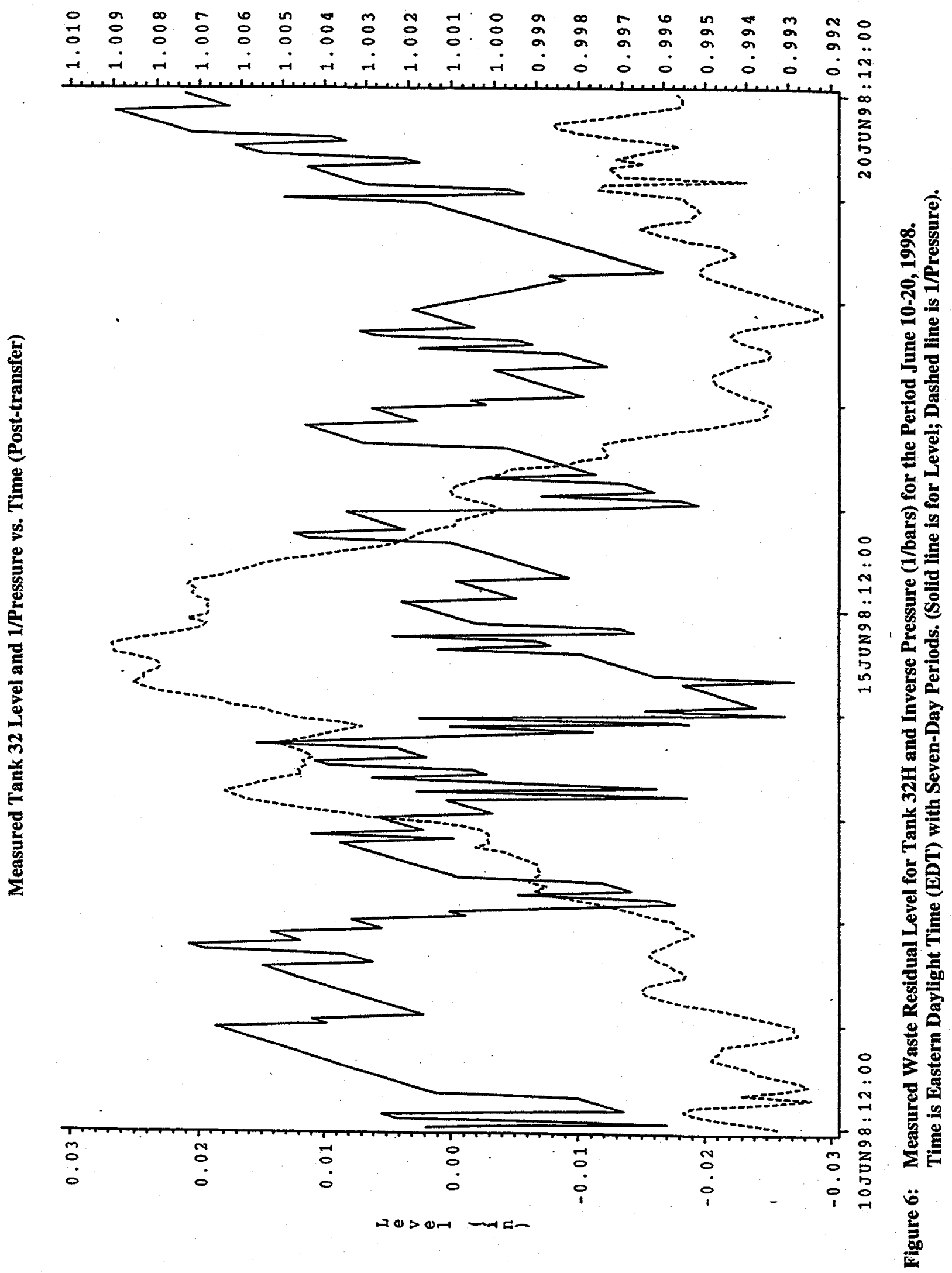


Spectrum of Pressure (Post-transfer)

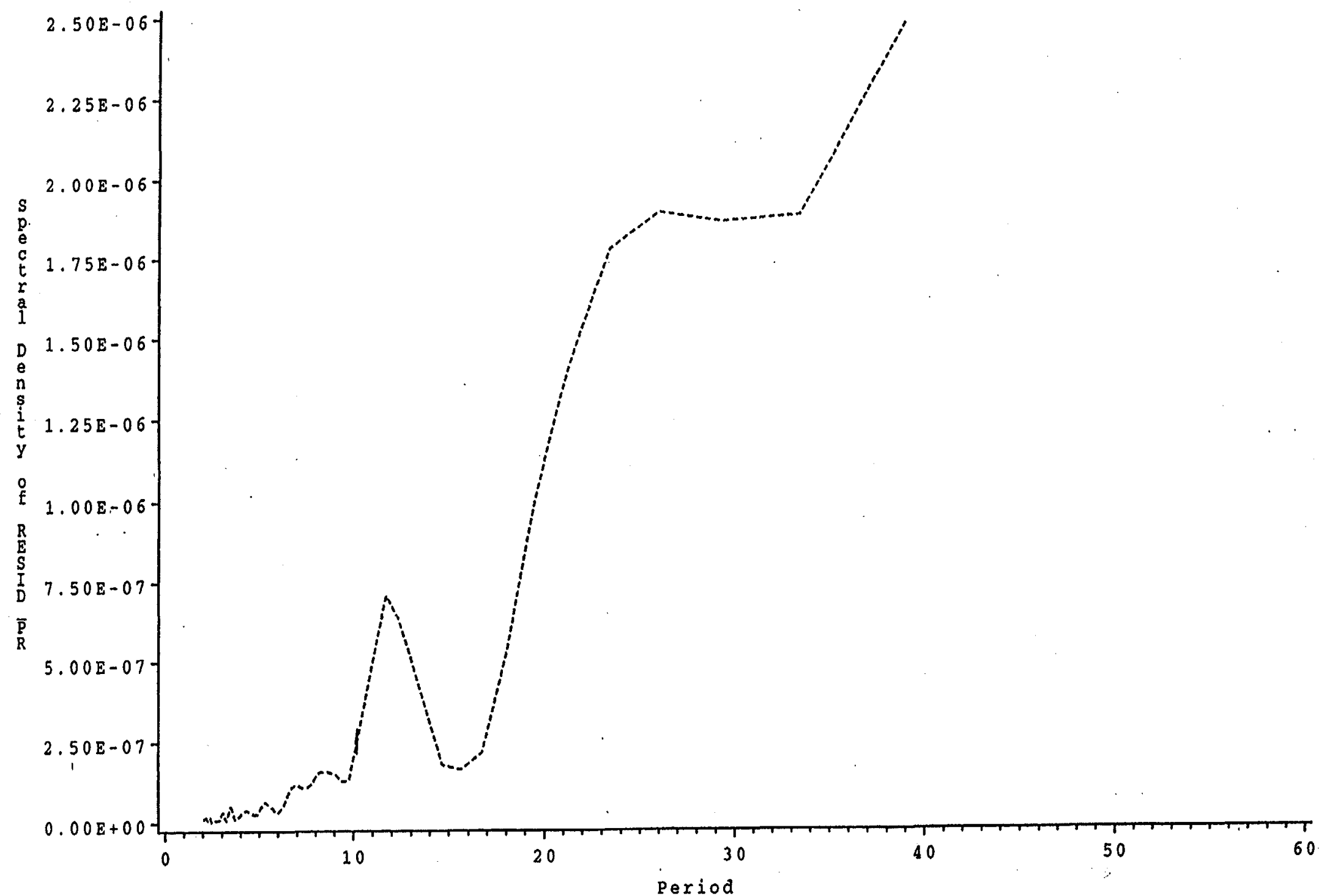

Figure 7: Spectral Density of Measured Atmospheric Pressure for the Period June 10-20, 1998. Period in Hours. 


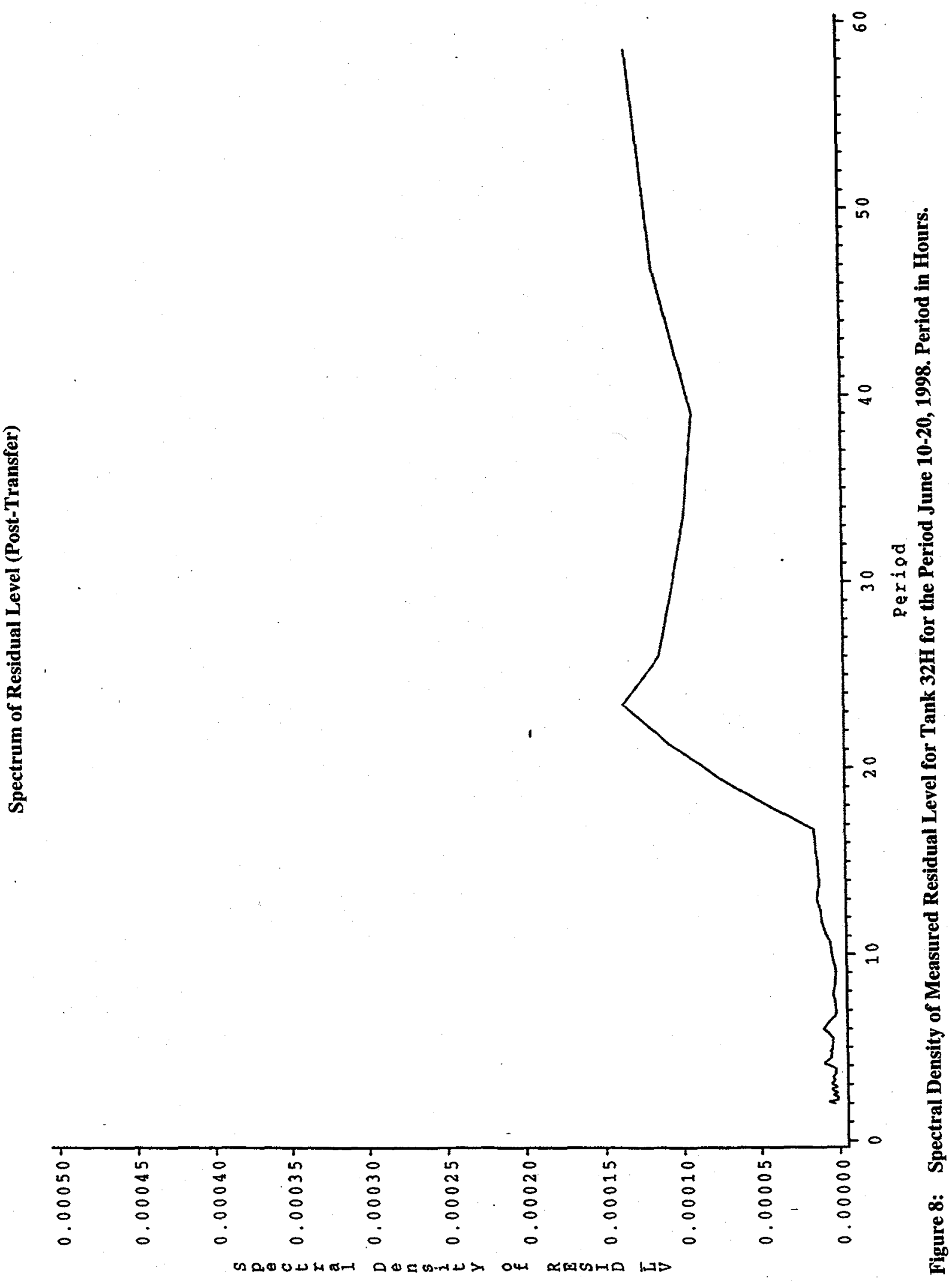




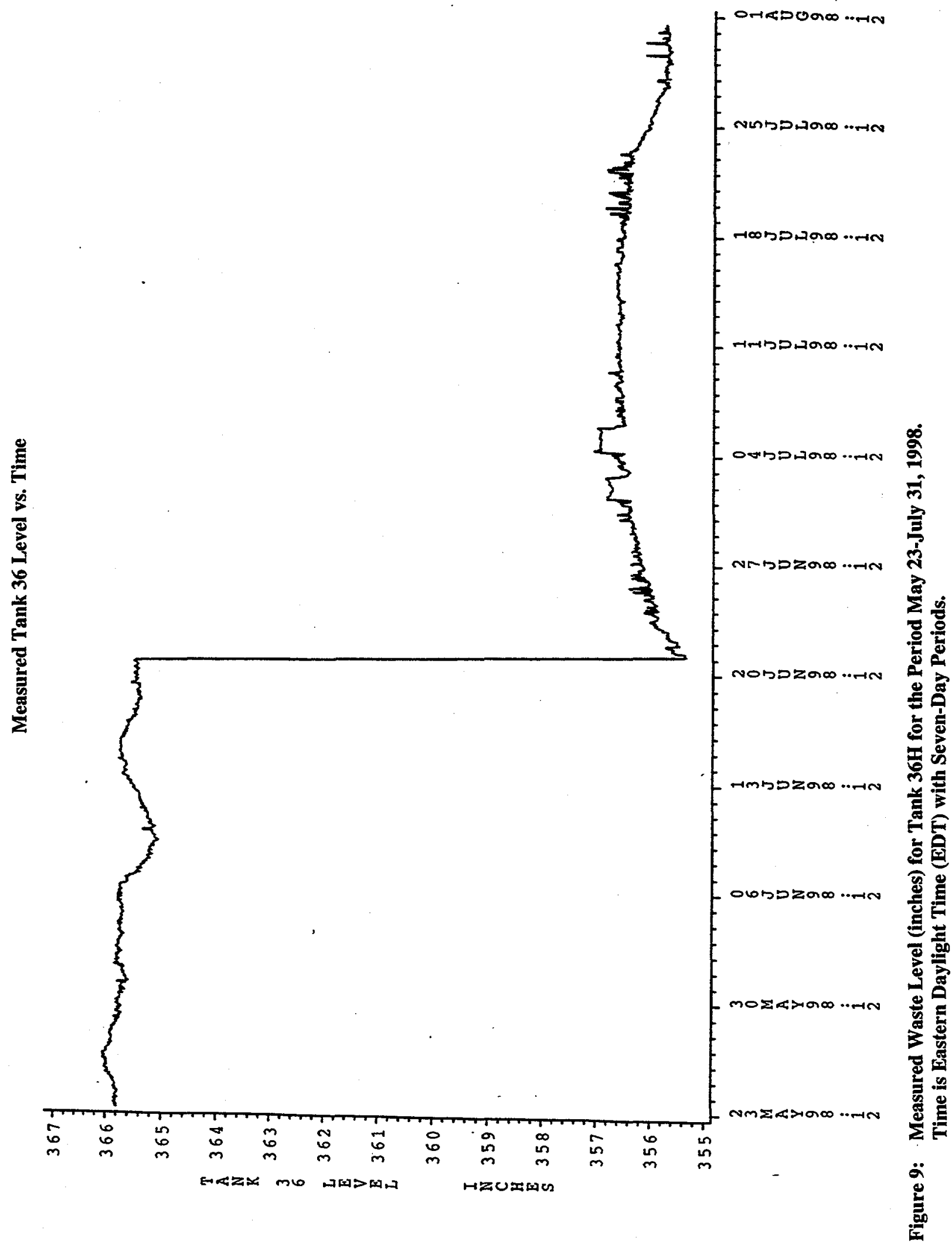




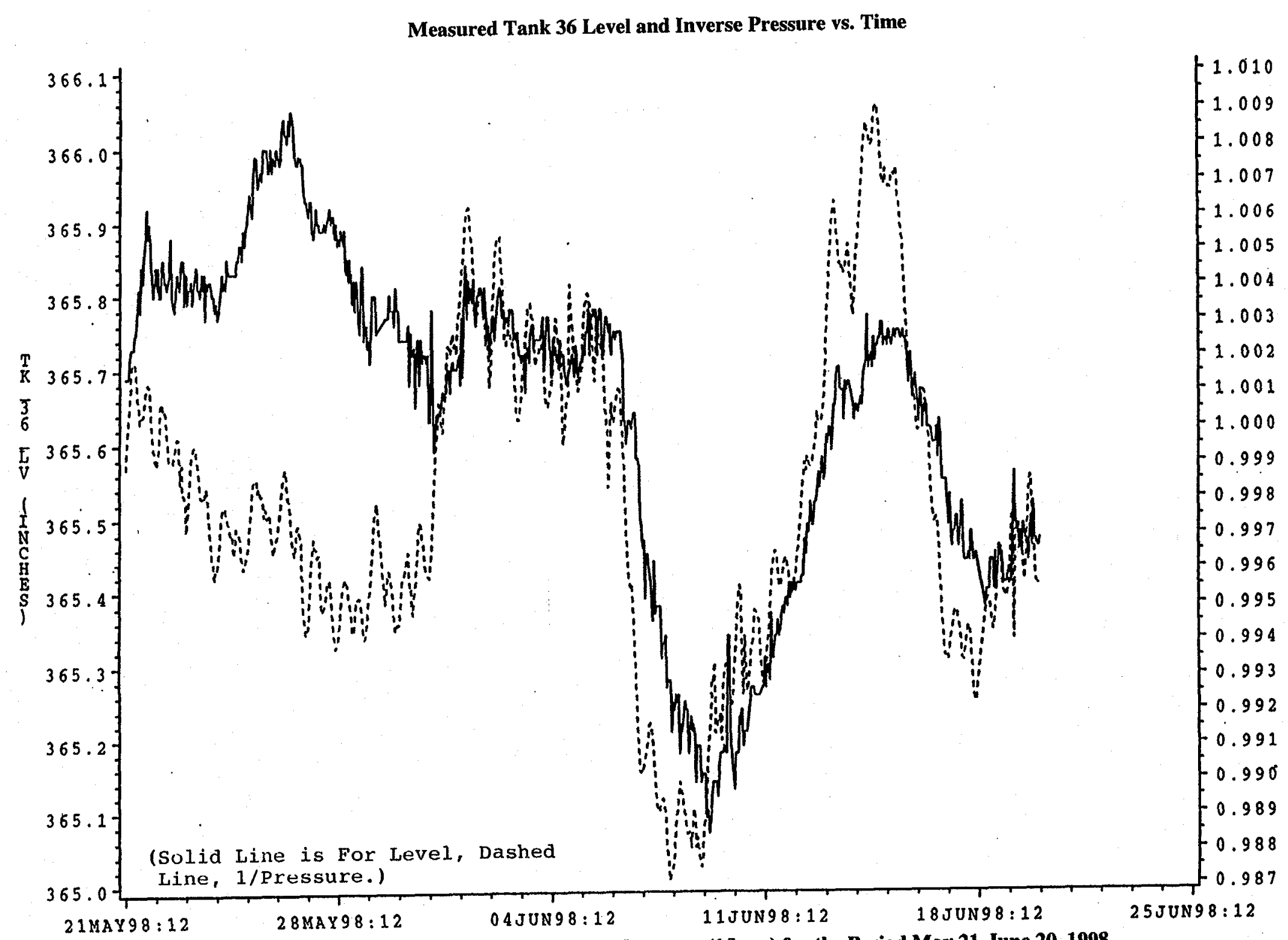

Figure 10: Measured Waste Level (inches) for Tank 36H and Inverse Pressure (1/bars) for the Period May 21-June 20, 1998.

Time is Eastern Daylight Time (EDT) with Seven-Day Periods. (Solid line is for Level; Dashed line is 1/Pressure). 
Measured Tank 36 Level and 1/Pressure vs. Time (Pre-transfer)

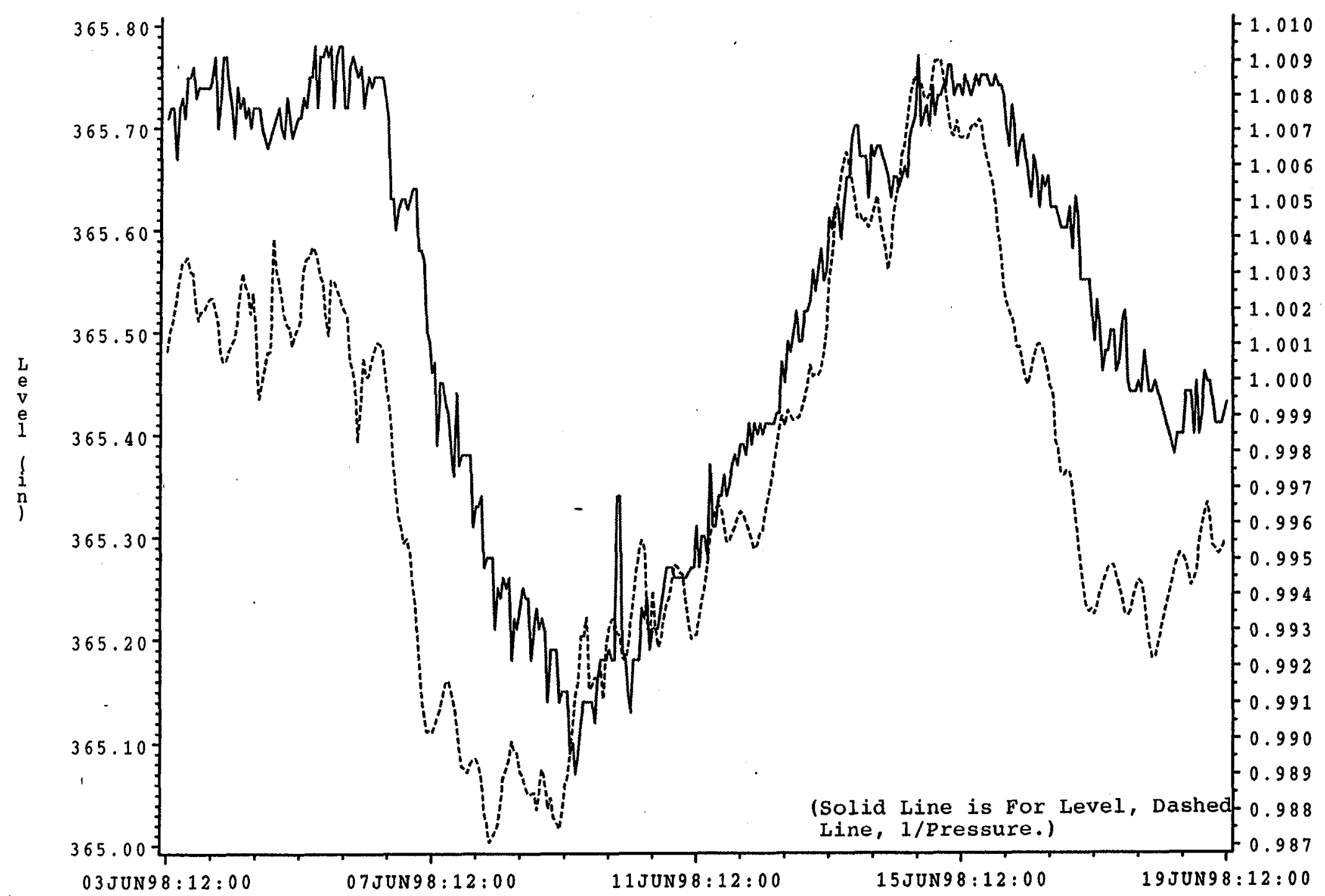

Figure 11: Measured Waste Residual Level for Tank 36H and Inverse Pressure (1/bars) for the Period June 3-19, 1998.

Time is Eastern Daylight Time (EDT) with Six-Day Periods. (Solid line is for Level; Dashed line is 1/Pressure). 


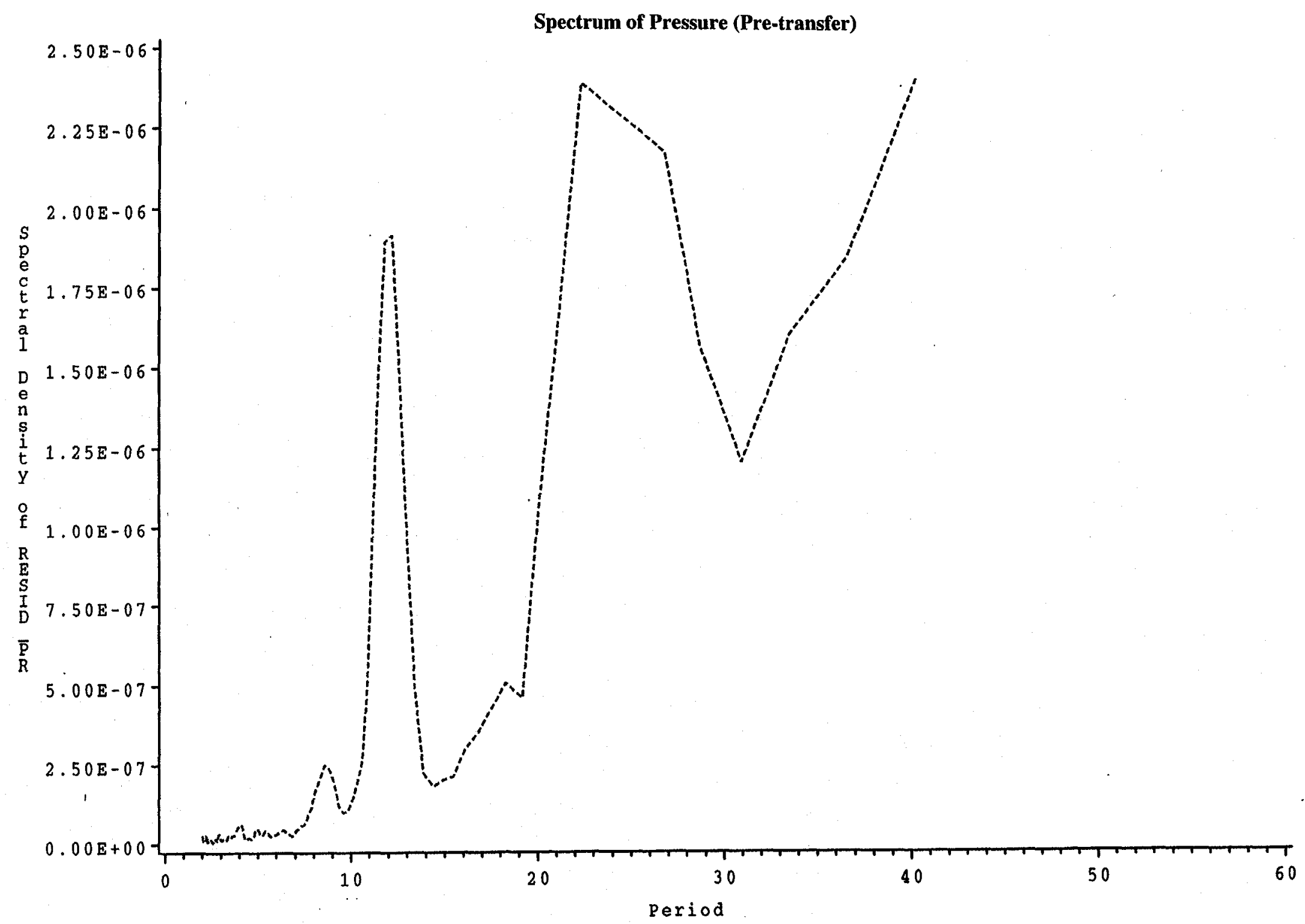

Figure 12: Spectral Density of Measured Atmospheric Pressure for the Period June 3-19, 1998. Period in Hours. 


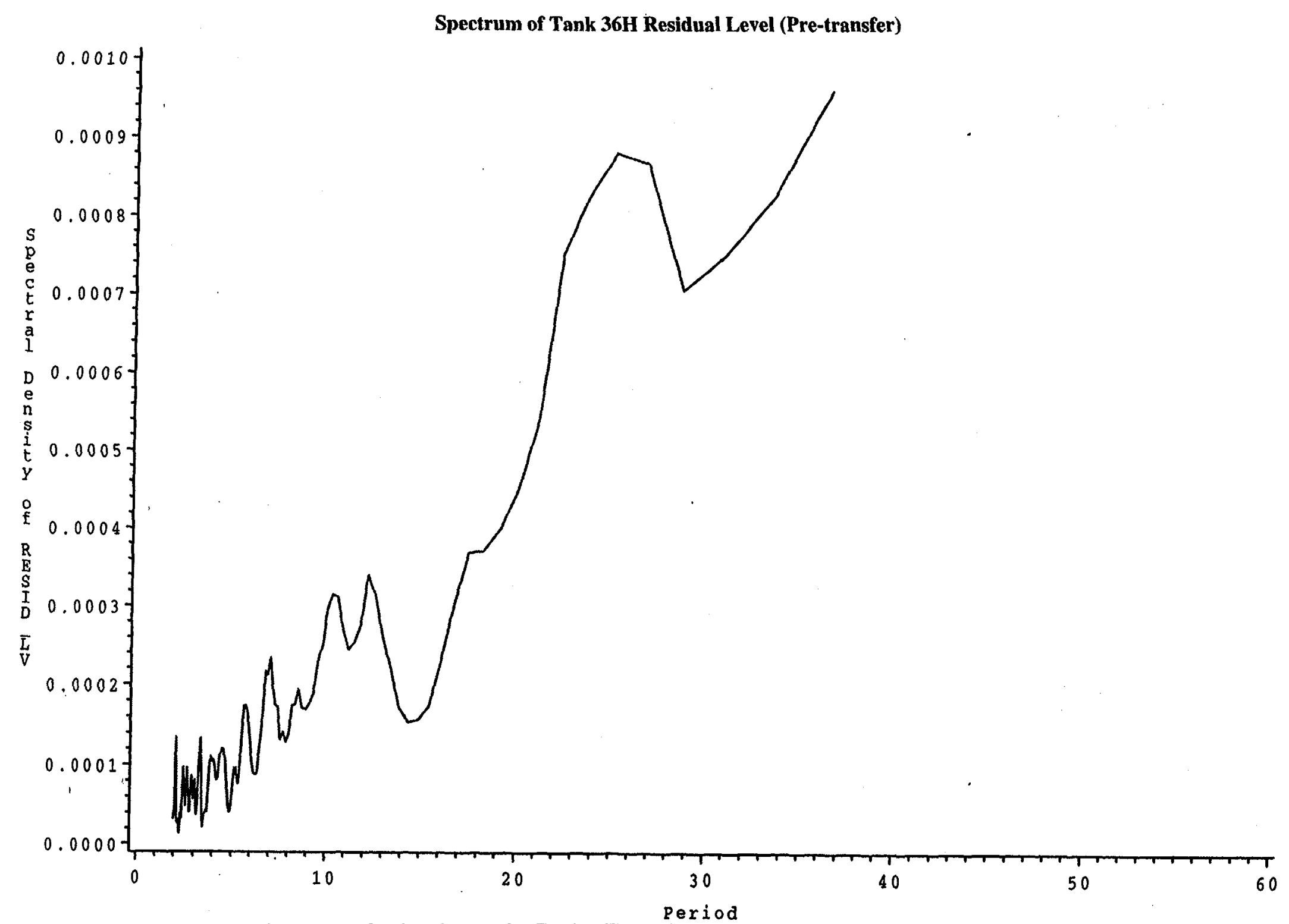

Figure 13: Spectral Density of Measured Residual Level for Tank 36H for the Period June 3-19, 1998. Period in Hours. 
Measured Tank 32 Level and 1/Pressure vs. Time (Post-transfer)

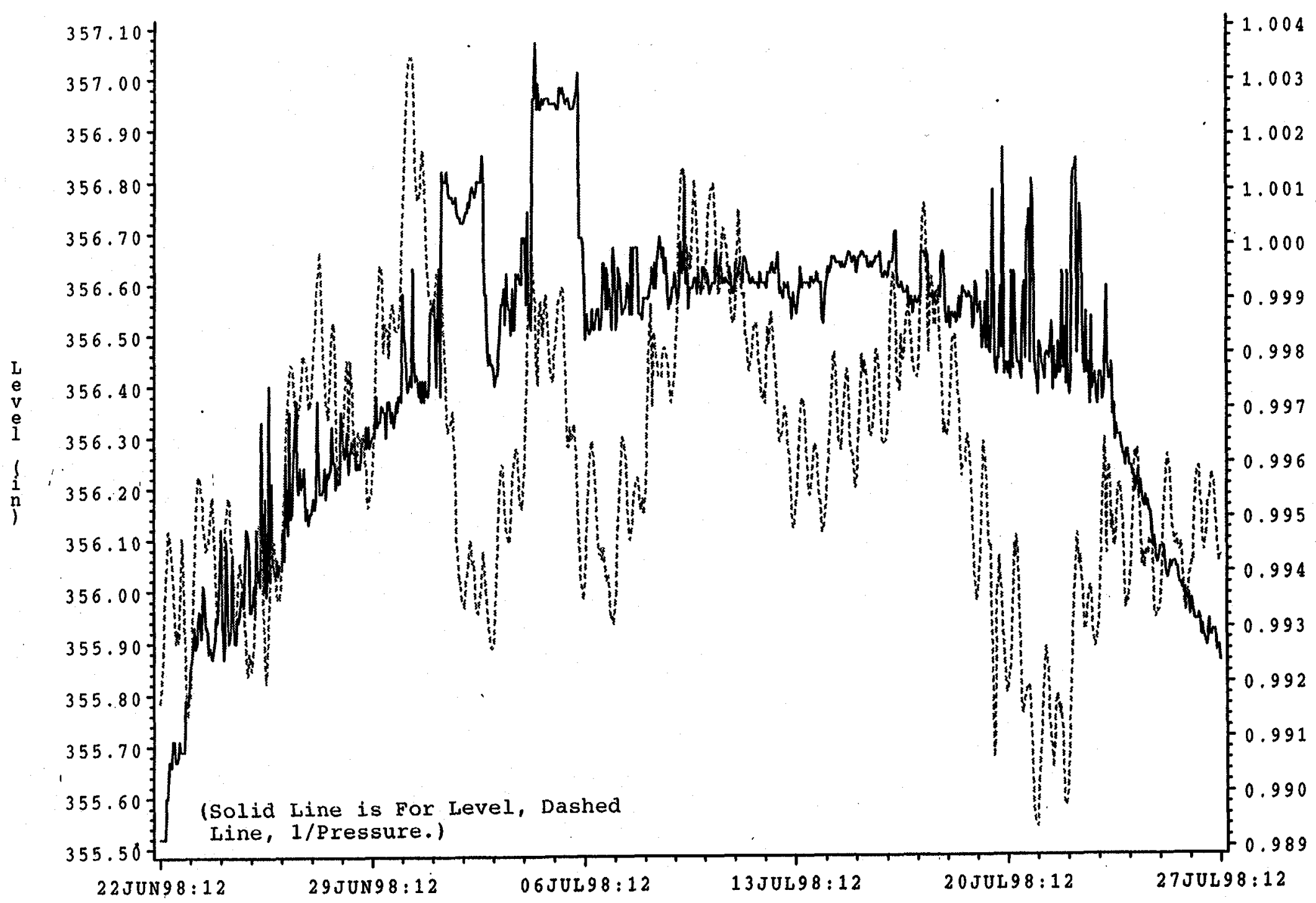

Figure 14: Measured Waste Residual Level for Tank 36H and Inverse Pressure (1/bars) for the Period June 22-July $27,1998$.

Time is Eastern Daylight Time (EDT) with Seven-Day Periods. (Solid line is for Level; Dashed line is 1/Pressure). 


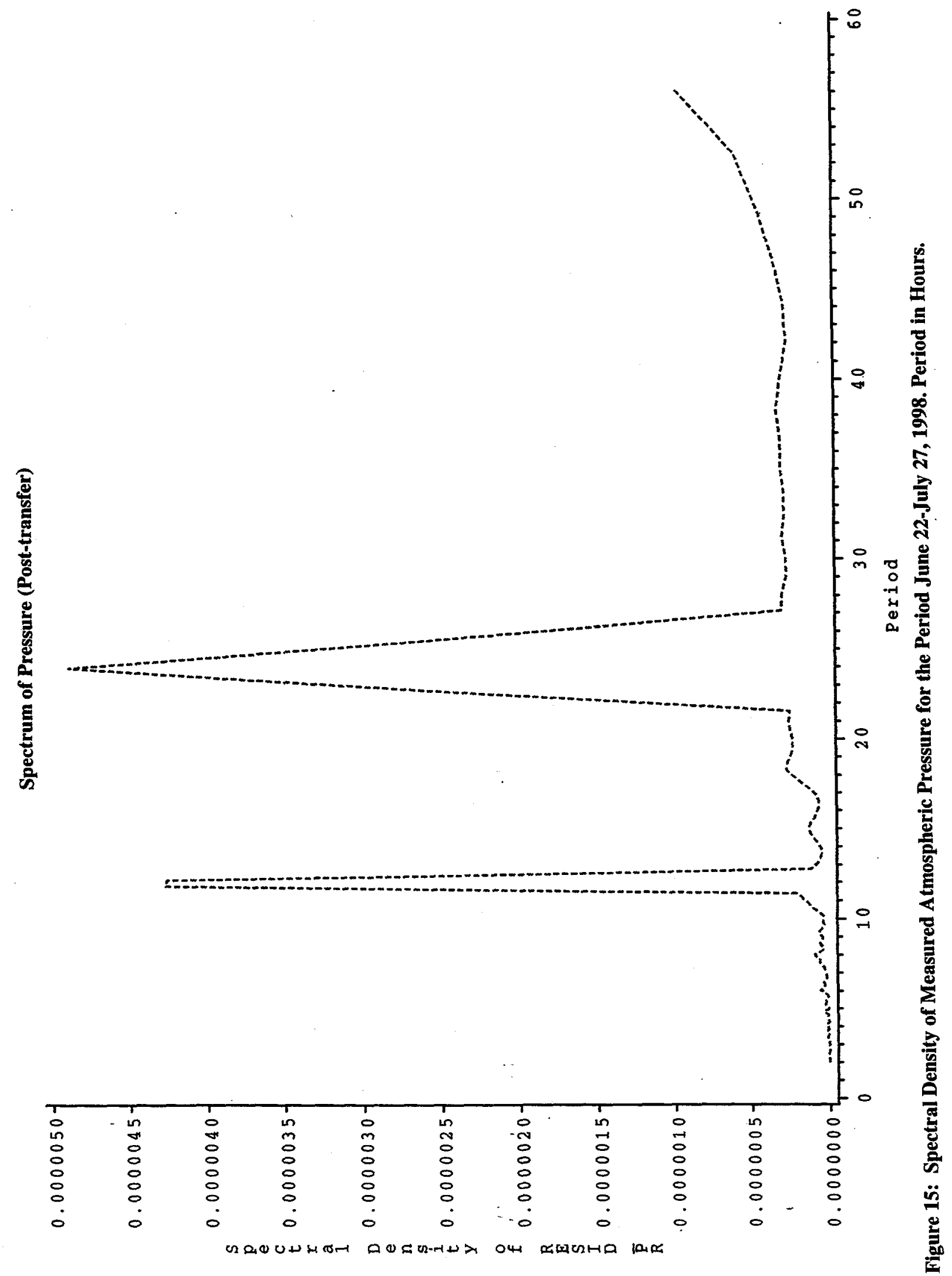




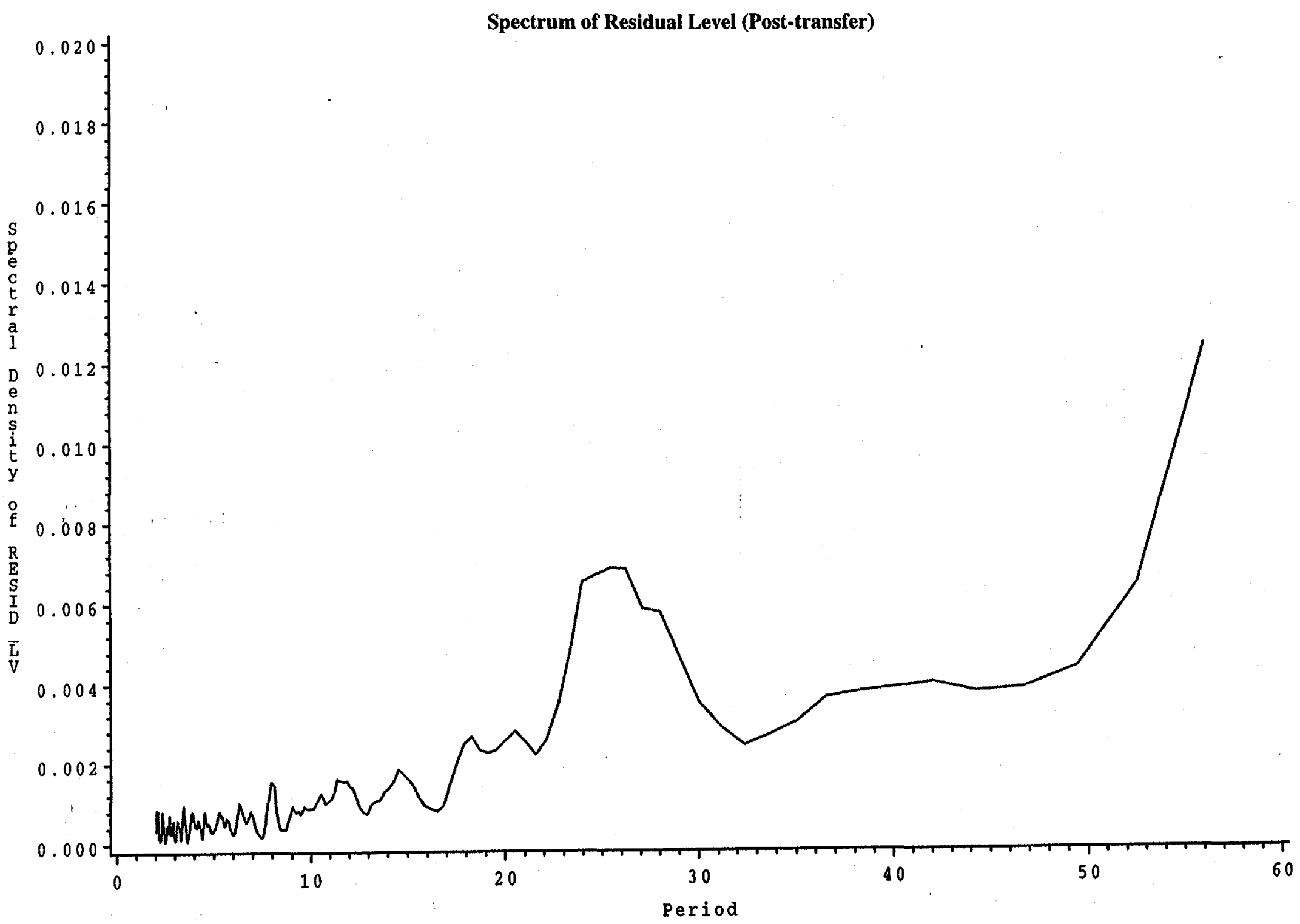

Figure 16: Spectral Density of Measured Residual Level for Tank 36H for the Period July 22-July 27, 1998. Period in Hours. 
Temperature vs. Time for Tanks $32 \mathrm{H}$ and $36 \mathrm{H}$

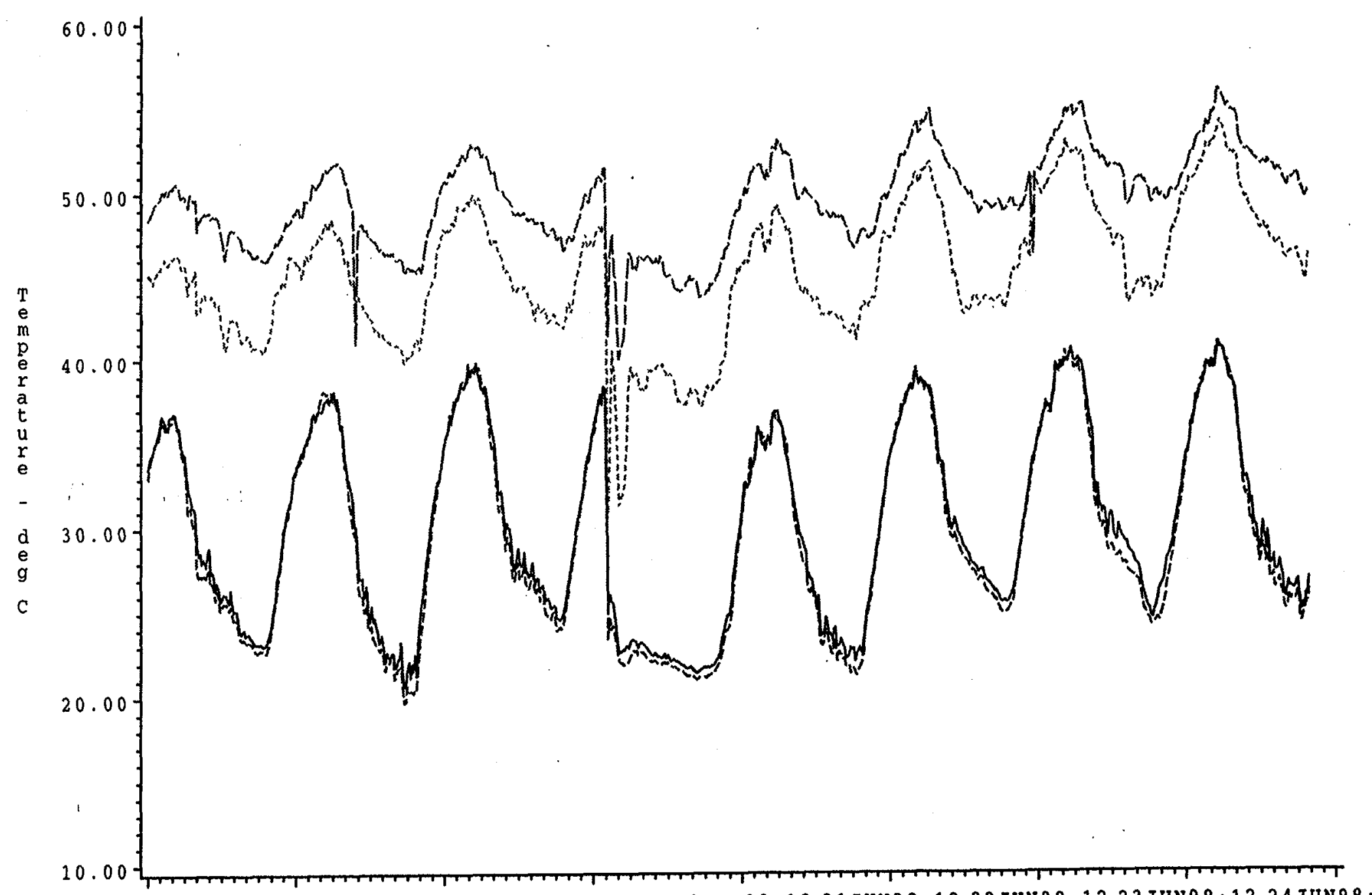

16JUN9 8:12 17JUN98:12 18JUN98:12 19JUN98:12 20JUN98:12 21JUN98:12 22JUN98:12 23JUN98:12 24JUN98:12

Figure 17: Time Series of Measured Temperatures (deg. C) for Tanks 32H and 36H. (Solid Tank 32H incoming air, light gray dash is Tank 32H outgoing air, dark gray dash is Tank 36H incoming air, long gray dash is Tank 36H outgoing air. 


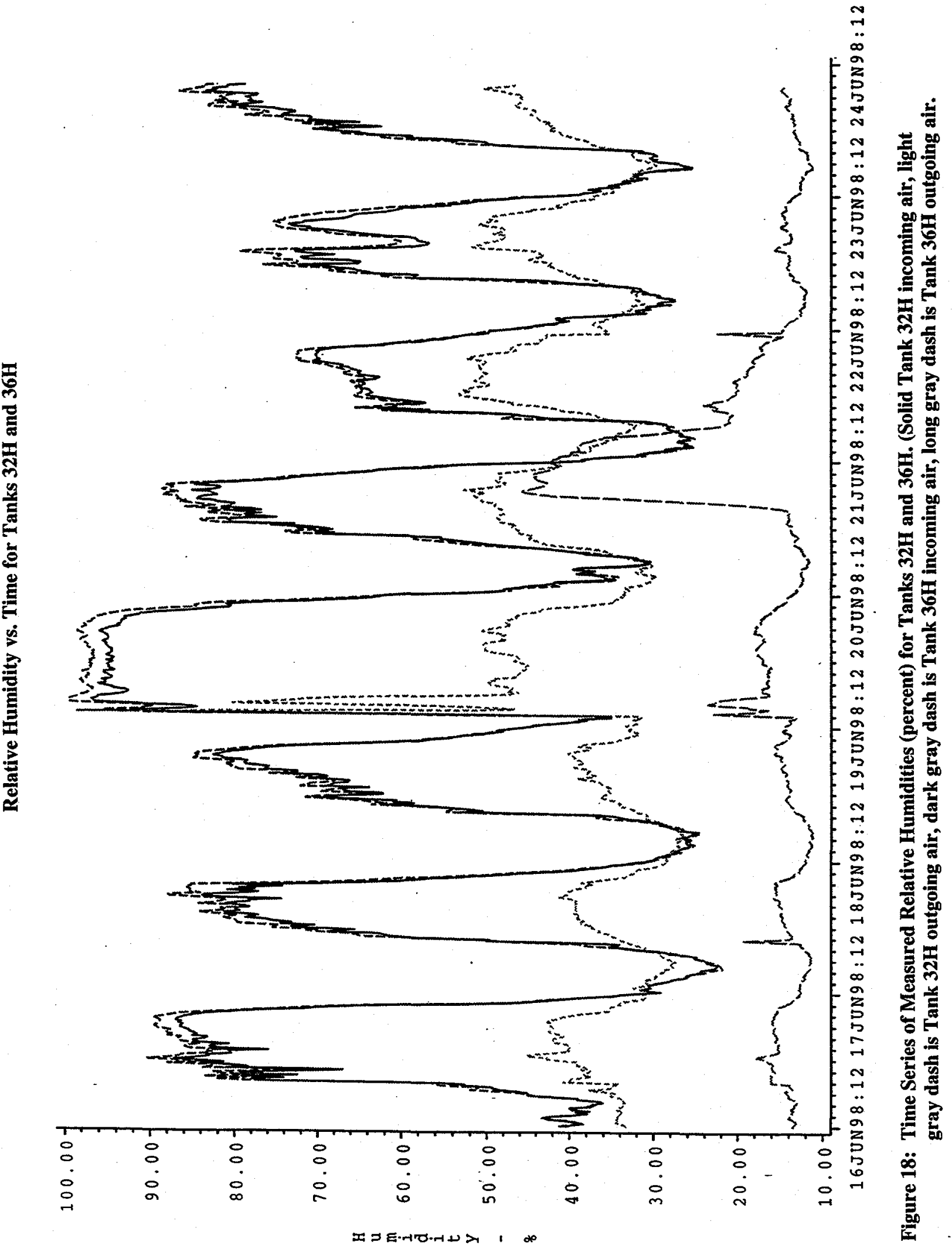




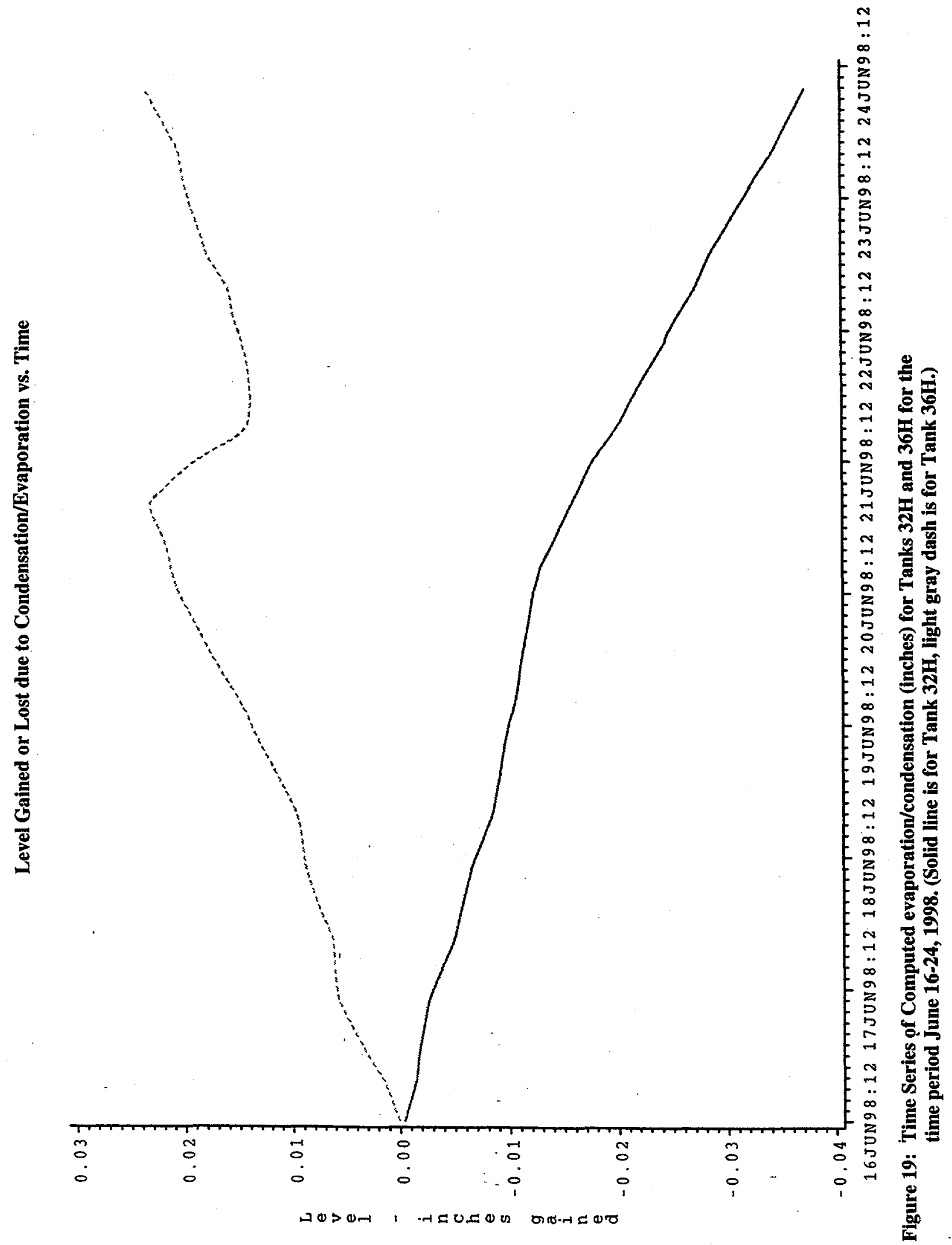

